\title{
TESES E DISSERTAÇÕES SOBRE ENVELHECIMENTO PRODUZIDAS NA UNIVERSIDADE FEDERAL DO RIO GRANDE DO SUL E INCLUIDAS NO SISTEMA DE BIBLIOTECAS NO ANO DE 2018
}

Sergio Antonio Carlos ${ }^{1}$

As teses e dissertações sobre envelhecimento produzidas na Universidade Federal do Rio Grande do Sul (UFRGS) e incluídas no Sistema de Bibliotecas no ano de 2018 são apresentadas nesta seção. O levantamento foi realizado a partir do Catálogo Online (SABi) e do Repositório Digital (LUME), utilizando-se os seguintes descritores: Antienvelhecimento; Cuidadores: idoso; Diagnóstico de enfermagem: idoso; Direitos dos Idosos; Educação: pessoa idosa; Enfermagem Geriátrica; Envelhecimento; Envelhecimento Celular; Envelhecimento da População; Geriatria; Gerontologia; Gerontologia Educacional; Idoso; Idoso de 80 anos ou mais; Idoso Fragilizado; Idoso: saúde; Longevidade; Memória (quando relacionada com o envelhecimento ou com pessoa idosa); Odontologia Geriátrica; Pessoa Idosa; Qualidade de vida: idoso; Saúde do Idoso; Terceira Idade; Velhice.

\footnotetext{
1 Membro da Comissão Editorial da Revista Estudos Interdisciplinares sobre o Envelhecimento. Professor titular aposentado e Professor Colaborador convidado junto ao Programa de Pós-Graduação de Política Social e Serviço Social da Universidade Federal do Rio Grande do Sul (UFRGS).
} 
Foram localizados 31 registros de teses e dissertações, 26 produzidas no ano de 2018 e 5 em 2017, mas incluída no Lume no ano seguinte. São 13 teses e 18 dissertações produzidas nos Programas de Pós-Graduação (PPGs) dos cursos de Administração; Antropologia Social; Ciências Biológicas: Bioquímica; Ciências Biológicas: Fisiologia; Ciências da Saúde: Cardiologia e Ciências Cardiovasculares; Ciências da Saúde: Ginecologia e Obstetrícia; Ciências do Movimento Humano; Ciências Médicas; Ciências Médicas: Endocrinologia; Comunicação e Informação; Direito; Educação; Enfermagem; Epidemiologia; Medicina: Ciências Médicas; Odontologia; e Programa de Pós-Graduação de Saúde Coletiva. O Programa de Pós-Graduação em Ciências do Movimento Humano da Escola de Educação Física, Fisioterapia e Dança (ESEFID) produziu neste período três teses e seis dissertações, fato que o coloca como o PPG em destaque pelo maior número de produções no período.

As teses e dissertações são apresentadas com seu resumo e indicação para a localização do texto completo no Repositório Digital da UFRGS (LUME). Só não apresentamos a indicação de acesso de cinco dissertações, o resumo de uma delas, bem como o resumo de uma tese por estas informações não estarem disponibilizadas no Sistema de Bibliotecas da UFRGS até o dia 28 de abril de 2018.

ARGENTA, Carla. Modelo multidimensional de cuidado ao idoso associado aos sistemas de linguagens padronizadas de enfermagem NANDA-I, NIC E NOC. Orientador: Amália de Fátima Lucena. 2018. 164 f. il. Tese (Doutorado em Enfermagem) - Escola de Enfermagem, Universidade Federal do Rio Grande do Sul, Porto Alegre, 2018. Disponível em: http://hdl.handle.net/10183/186134. Acesso em: 26 abr. 2019.

\section{resumo}

O cuidado integral ao idoso pode ser garantido mediante a utilização do Processo de Enfermagem (PE), aliado a um referencial teórico como, por exemplo, o Modelo Multidimensional de Envelhecimento bem Sucedido (MMES), que possui uma proposta de avaliação do idoso. Há, contudo, uma lacuna para a sua utilização, uma vez que não há estudos que comprovem a sua eficácia na prática clínica da Enfermagem associado à aplicação de sistemas de classificação da disciplina como a NANDA-I, NIC e NOC. O objetivo deste estudo é construir um modelo multidimensional de cuidado ao idoso associado aos Sistemas de Linguagens Padronizadas de Enfermagem NANDA-I, NIC e NOC, aplicável à consulta de enfermagem. O estudo foi conduzido em 
duas etapas metodológicas distintas. A primeira compreendeu um estudo de validação de conteúdo enquanto a segunda uma pesquisa de resultados, que contemplou um estudo quase experimental. As amostras foram constituídas de 15 especialistas em Enfermagem Gerontológica e 28 idosos em primeira consulta na Cidade do Idoso, local do estudo, com idade igual ou superior a 60 anos, que apresentaram o diagnóstico de enfermagem Risco de Síndrome do Idoso Frágil (RSIF) ou Síndrome do Idoso Frágil (SIF), no período de maio a outubro de 2017. Após a validação do conteúdo do modelo multidimensional, com a opinião dos especialistas, efetuou-se a sua aplicação aos idosos em quatro consultas de enfermagem para cada um. Durante as consultas estabeleceram-se os diagnósticos, mensuraram-se os resultados e implementaram-se as intervenções de enfermagem, conforme o modelo e a avaliação clínica. Os especialistas validaram informações da anamnese e exame físico referentes às características definidoras, fatores relacionados e de risco dos dois diagnósticos e às dimensões fisiológica, psicológica e social, conforme propõe o MMES. A validação também confirmou que dos 13 diferentes resultados de enfermagem validados, 10 foram comuns em ambos os diagnósticos. Os resultados validados para os dois diagnósticos avaliaram Equilíbrio (0202), Cognição (0900), Estado nutricional (1004), Autocontrole da doença crônica (3102), Conhecimento: controle da dor (1843), Participação em programa de exercício físico (1633), Conhecimento: controle da doença crônica (1847), Conhecimento: prevenção de quedas (1828), Conhecimento: controle do peso (1841) e Estado de conforto (2008). Apenas dois dos 13 resultados foram validados para o diagnóstico SIF, sendo eles: Nível de fadiga (0007) e Autocuidado: atividades da vida diária (0300), e um resultado, Conhecimento: medicamento (1808), foi validado apenas para o diagnóstico RSIF. As intervenções de enfermagem da NIC, validadas para os dois diagnósticos de enfermagem, foram praticamente iguais. Das oito diferentes intervenções validadas apenas a Assistência ao Autocuidado (1800) foi validada exclusivamente para o diagnóstico SIF e as outras sete foram validadas para os dois diagnósticos. As intervenções destacam a importância da Promoção do exercício (0200), Aconselhamento nutricional (5246), Controle de medicamentos (2380), Estimulação cognitiva (4720), Melhora na socialização (5100), Prevenção contra quedas (6490) e Ensino sobre o processo da doença (5602). A segunda etapa mostrou que dos 28 idosos a maioria era do sexo feminino (17 - 60,7\%), com idade média de 65,6 6 6,3 anos e, desses, 23 idosos foram diagnosticados com RSIF e cinco com SIF. Dos resultados de enfermagem utilizados para avaliar idosos com RSIF e SIF percebeu-se melhora significativa na média dos escores dos seus indicadores: Participação em programa de exercício físico; Autocontrole da doença crônica; 7 Conhecimento: controle da 
doença crônica; Conhecimento: controle do peso; Conhecimento: prevenção de quedas e Estado de conforto. Os resultados Estado nutricional e Conhecimento: controle da dor tiveram melhora significativa nos escores dos indicadores somente para idosos com RSIF, assim como a avaliação do Autocuidado: atividades da vida diária para idosos com SIF. As intervenções que apresentaram efetividade estatisticamente significativa na utilização de suas atividades em idosos, com ambos os diagnósticos, foram: Ensino: processo da doença e Promoção do exercício, enquanto a intervenção Prevenção contra quedas foi encontrada somente em idosos com RSIF. Conclui-se que as sete intervenções de enfermagem validadas pelos especialistas foram implementadas aos idosos com diagnóstico de enfermagem RSIF e foram consideradas efetivas, tendo como base a avaliação de nove resultados que apontaram melhora significativa na comparação entre as médias da primeira e quarta consultas. Dentre as oito intervenções de enfermagem implementadas aos idosos com diagnóstico de enfermagem SIF, sete foram consideradas efetivas, tendo como base a avaliação de 11 resultados que apontaram melhora significativa na comparação entre as médias da primeira e quarta consultas. Dessa forma, conclui-se ainda, que o modelo multidimensional de cuidado ao idoso associado aos SLP contribui para a prática assistencial do enfermeiro na consulta de enfermagem, com vistas ao envelhecimento bem sucedido. Dentre as importantes implicações e contribuições dos resultados desta pesquisa está a possibilidade de apoiar a ligação entre resultados e intervenções validados com os diagnósticos de enfermagem RSIF e SIF, facilitando a avaliação de enfermagem e os cuidados de enfermagem aos idosos na prática clínica. Além disso, recomenda-se a construção de definições operacionais para os indicadores dos resultados de enfermagem. Uma limitação do estudo foi o fato de realizarmos a pesquisa com especialistas do mesmo país.

palavras-chave

Avaliação de Resultados (Cuidados de Saúde). Diagnóstico de Enfermagem: Classificação. Modelos de Enfermagem. Paciente Idoso. Processo de Enfermagem.

ÁVILA, Ana Luiza. Consumo midiático de televisão e recepção do fluxo publicitário televisivo pelo público idoso. Orientador: Elisa Reinhardt Piedras. 2018. il. Dissertação (Mestrado em Comunicação e Informação) - Faculdade de Biblioteconomia e Comunicação, Universidade Federal do Rio Grande do Sul, Porto Alegre, 2018. Disponível em: http://hdl.handle.net/10183/174817. Acesso em: 27 abr. 2019. 
Esta pesquisa tem como objetivo compreender o consumo midiático da televisão e a recepção do fluxo publicitário televisivo pelo idoso. No âmbito teórico aborda-se a comunicação e a cultura via Estudos Culturais, valendo-se, especialmente, do Novo Mapa das Mediações (MARTÍN-BARBERO, 2003), das práticas de consumo midiático da televisão e da recepção do fluxo publicitário. Trata-se, também, das especificidades do público idoso e da narrativa da memória. Na fase empírica, a pesquisa é qualitativa e realizada através da técnica de entrevista semiaberta, com uma unidade de pesquisa composta por seis idosos (três homens e três mulheres, com níveis de escolaridade que variam entre ensino médio e superior completo, residentes na cidade de Porto Alegre/RS e entorno). Os resultados apontam como ocorrem as práticas de consumo midiático da televisão, a recepção do fluxo publicitário televisivo e a relação entre o fluxo publicitário televisivo ofertado e o apropriado pelos informantes da pesquisa. Concluiu-se que o tempo simbólico dedicado a essas práticas está relacionado ao descanso e ao lazer, sendo que o que pauta o consumo midiático é o interesse na informação e no entretenimento. O idoso assiste a maioria dos anúncios ofertados no fluxo publicitário televisivo e o rejeita quando não corresponde às suas competências culturais.

\section{palavras-chave}

Estudo de Recepção. Idoso. Publicidade. Televisão (Comunicação).

BEZ, Andressa da Silveira. Avaliação das propriedades psicométricas da escala de bem-estar psicológico. Orientador: Juliana Balbinot Hilgert. 2018. 120 f. il. Tese (Doutorado em Odontologia) - Faculdade de Odontologia, Universidade Federal do Rio Grande do Sul, Porto Alegre, 2018. Disponível em: http://hdl.handle. net/10183/183169. Acesso em: 27 abr. 2019.

resumo

Bem-Estar Psicológico é um construto multidimensional baseado no funcionamento psicológico positivo. Para mensurar sua teoria, Ryff propôs uma escala de seis dimensões, com versões de 120, 84, 54 e 18 itens. Este trabalho tem como um de seus objetivos revisar sistematicamente estudos de validação das versões da Escala de Bem-Estar Psicológico de Ryff, sumarizando as 
propriedades psicométricas das mesmas. Foram incluídos estudos quantitativos que utilizaram a escala de Bem-Estar Psicológico, considerando as versões originais de 120, 84, 54 e 18 itens. Foram considerados elegíveis apenas os estudos sobre a validação da escala de Ryff em quaisquer versões e estudos com diferente número de itens oriundos das versões originais citadas anteriormente. Como estratégia de busca incluiu-se às bases de dados indexados Scopus e National Library of Medicine (Pubmed). A primeira estratégia de busca consistiu de palavras e descritores de Bem-Estar Psicológico. A segunda estratégia de busca adicionou palavras para especificar publicações na área de psicometria. Foram encontrados 38 artigos, totalizando 54 estudos, pois alguns artigos possuem mais de um estudo. A versão de 18 itens foi a mais validada, com 16 estudos, o espanhol foi a língua mais utilizada, a maioria dos artigos realizou análise fatorial e grande parte das amostras era composta por adultos com alto nível de escolaridade. O outro objetivo é realizar a análise fatorial exploratória com diferentes versões da Escala de Bem-estar Psicológico de Ryff de 18 itens e realizar a análise fatorial confirmatória com o modelo que apresentou melhor ajuste. Trata-se de um estudo transversal aninhado a uma coorte, cuja amostra foi de 389 idosos. Os dados desse estudo foram obtidos a partir da coorte de Carlos Barbosa que tinha como objetivo avaliar a saúde geral, bucal e psicológica e estado nutricional de idosos vivendo de maneira independente neste município. Foi realizada análise fatorial exploratória para avaliar a estrutura dimensional da escala de 18 itens e análise fatorial confirmatória para o modelo de melhor ajuste. Conclui-se que a escala de Bem-Estar Psicológico não é culturalmente dependente e que há necessidade de modificação de alguns itens para que o construto seja corretamente aplicado e compreendido na amostra estudada.

palavras-chave

Bem-estar. Idoso. Psicometria. Validação.

BIELAWSKI, Flávia Regina Tavares Nunes. As vivências de lazer com os idosos do Parque Alim Pedro: um estudo etnográfico. Orientador: Marco Paulo Stigger. 2018. 109 f. il. Dissertação (Mestrado em Ciências do Movimento Humano) - Escola de Educação Física, Fisioterapia e Dança, Universidade Federal do Rio Grande do Sul, Porto Alegre, 2018. Disponível em: http://hdl.handle.net/10183/184682. Acesso em: 27 abr. 2019. 
A presente pesquisa objetivou compreender como os idosos significam suas práticas de lazer vivenciadas nos grupos de convivência dos quais fazem parte promovidos pela Prefeitura Municipal de Porto Alegre/RS, desenvolvidos no Parque Alim Pedro. Na busca de alcançar esse objetivo, foi desenvolvida uma etnografia durante os meses de setembro a dezembro de 2017, período em que vivenciei as atividades das modalidades: "Reeducação Postural", "Ritmos" e "Caminhada Orientada". Juntamente com os idosos e professores participei de diversas atividades que eram realizadas cotidianamente, incluindo as rodas de conversas, as confraternizações, os ensaios e as apresentações. Todas estas vivências foram relatadas nos meus diários de campo. No mês de março de 2018 realizei 27 entrevistas com os idosos participantes destas práticas de lazer e 3 entrevistas com os professores. Após este período de imersão na realidade estudada, os dados empíricos desta pesquisa foram analisados e interpretados e, com isso, desenvolvi as categorias de análise. O universo e contexto do local estudado foram abordados no primeiro capítulo juntamente com a descrição e as características dos três grupos pesquisados. Após essa contextualização descrevo as categorias de análises: a "Adesão às Atividades", onde os idosos relataram que aderiram as atividades pelos mais variados motivos, dentre eles a prática durante toda a vida, a aposentadoria, o incentivo de amigos ou parentes, a busca por atividades que amenizem os fatores negativos do envelhecimento e recomendação médica. Na segunda categoria, "Os Cuidados com a Saúde", pude constatar que a busca e consequentemente, a manutenção da saúde aliada as preocupações com a estética são fatores influenciadores para a permanência dos idosos nas práticas de lazer desenvolvidas no Parque Alim Pedro. Na terceira categoria, "Autonomia e Independência" foi evidenciado que os participantes desta pesquisa associam as práticas de lazer com as melhorias na saúde física, propiciando melhoras na capacidade funcional dos idosos. A quarta, e última categoria, "O Bem-estar e as Práticas de Lazer" os participantes demostraram que as atividades realizadas no Parque Alim Pedro possibilitam maior sociabilidade, favorecendo a noção de pertencimento, o que impulsiona a permanência nas atividades. Diante dessas categorias, finalizo os resultados fazendo uma reflexão acerca de uma possível Necessidade/ Obrigatoriedade do Lazer para o público idoso. Frente aos resultados obtidos, na conclusão deste estudo procurei estabelecer um diálogo com algumas concepções do lazer, tendo em vista algo que me pareceu paradoxal: por um lado o lazer é visto como algo distante das obrigações, algo que 'se escolhe', por outro, parece existir autoconsciência da necessidade/obrigatoriedade de 
participação nessas práticas para pessoas dessa faixa etária. Fica, assim, um questionamento: as vivências de lazer, para o público idoso, não acabam por ser "obrigatórias/necessárias"?

palavras-chave

Idoso. Lazer. Pertencimento. Práticas Corporais. Sociabilidade.

COHEN, Rachel. A "ordem discursiva" sobre o envelhecimento ativo: como ser velho e saudável hoje? Orientador: Cristianne Maria Famer Rocha. 2018. 89 f. il. Dissertação (Mestrado em Saúde Coletiva) - Escola de Enfermagem, Universidade Federal do Rio Grande do Sul, Porto Alegre, 2018. Disponível em: http://hdl.handle.net/10183/187924. Acesso em: 27 abr. 2019.

resumo

Nos últimos anos, o envelhecimento populacional tornou-se um tema em ascensão, compondo discussões nas áreas política, social, econômica e cultural. Com isto, percebe-se a alta frequência com que certos termos vêm sendo utilizados, muitas vezes desacompanhados de maiores reflexões sobre esta utilização e o significado dos mesmos. Entre eles, o Envelhecimento Ativo passa a receber cada vez mais destaque nas agendas, ganhando força com a publicação da Política de Envelhecimento Ativo pela Organização Mundial da Saúde (OMS), em 2005, que o define como o processo de otimização de oportunidades de saúde, participação e segurança, que possibilita aumentar a expectativa de uma vida saudável e com qualidade para todas as pessoas que estão envelhecendo, independente de sua condição de saúde. Entretanto, por vezes, a busca pelo Envelhecimento Ativo pode parecer guiar o indivíduo por um trajeto permeado de obrigatoriedades, com atividades e comportamentos a serem estimulados ou rejeitados, entrelaçados a uma lógica biomédica que pode assumir o status de verdade. Esta Dissertação tem como objetivo analisar como certas "verdades" sobre o tema do Envelhecimento Ativo vêm sendo publicadas e a quais conteúdos esta expressão vem sendo associada. Para isso, estruturamos dois artigos, que compõe os resultados desta pesquisa e que buscaram conhecer o que vem sentido dito, na literatura científica e na mídia, em particular no jornal Folha de São Paulo, a respeito do Envelhecimento Ativo. O primeiro artigo se trata de uma pesquisa bibliográfica, na qual a busca pelos artigos científicos foi feita no Portal de Periódicos da Coordenação de 
Aperfeiçoamento de Pessoal de Nível Superior (CAPES), através da utilização do termo Envelhecimento Ativo. Foram incluídas publicações de periódicos revisados por pares, entre os anos de 2007 a 2014, em idioma português, o que resultou em uma amostra composta por 18 publicações. Verificou-se que apesar do uso da expressão Envelhecimento Ativo ser cada vez mais frequente na literatura científica brasileira, ainda são escassos os materiais que tecem uma análise crítica acerca da expressão e suas possíveis formas de implicação na vida e na saúde dos indivíduos. O segundo artigo busca conhecer e analisar o discurso sobre o Envelhecimento Ativo, através de reportagens do jornal Folha de São Paulo, ao entender o poder que a mídia exerce na construção de sentidos. A análise utilizou ferramentas propostas por Michel Foucault, como as noções de discurso, mecanismos de segurança e governamentalidade. As reportagens, em um total de oito, auxiliam a compreender como o discurso sobre o Envelhecimento Ativo estabelece na contemporaneidade formas de ser e agir aos indivíduos idosos, associando o envelhecer ativamente a um ideal a ser desejado e buscado pela população idosa. Esta Dissertação tentou evidenciar como as diferentes publicações sobre o tema parecer orientar o idoso a ser melhor, mais feliz e mais saudável. No entanto, podem lançar o indivíduo na busca cega destes objetivos, regulamentando sua existência através de normas, números e porcentagens, que pouco dialogam com a realidade e cotidiano dos idosos.

palavras-chave

Envelhecimento. Qualidade de Vida. Saúde do Idoso.

DAL PIZZOL, Fernanda Laís Fengler. Adaptação e validação da escala de capacidades do cuidador informal de idosos dependentes por AVC (ECCIID-AVC) para uso no Brasil. Orientador: Lisiane Manganelli Girardi Paskulin. 2018. 162 f. il. Dissertação (Mestrado em Enfermagem) - Escola de Enfermagem, Universidade Federal do Rio Grande do Sul, Porto Alegre, 2018. Disponível em: http://hdl. handle.net/10183/179384. Acesso em: 27 abr. 2019.

resumo

O Acidente Vascular Cerebral (AVC) é a doença cerebrovascular mais prevalente na população idosa e uma das principais causas de incapacidade funcional. A Escala de Capacidades do Prestador Informal de Cuidados de 
Idosos Dependentes por AVC (ECPICID-AVC), desenvolvida em Portugal, avalia 32 capacidades que cuidadores informais devem possuir para apoiar os idosos sobreviventes de AVC. O objetivo deste estudo foi adaptar e validar a escala ECPICID-AVC para uso com cuidadores informais de pessoas idosas sobreviventes de AVC no Brasil. Trata-se de estudo metodológico dividido em duas etapas: adaptação transcultural e validação. A adaptação transcultural contou com as subetapas: Comitê de Especialistas, Pré-Teste e Submissão do documento aos autores do instrumento original. A validação envolveu coleta de dados e avaliação das propriedades psicométricas. A pesquisa foi realizada no Hospital de Clínicas de Porto Alegre (HCPA) e Grupo Hospitalar Conceição (GHC). Para avaliação das propriedades psicométricas foram verificadas as características de fidedignidade e a validade dos resultados (validades de conteúdo e constructo). A consistência interna dos itens que compõem a escala foi investigada por meio do alfa de Cronbach e da Correlação Intraclasse (ICC) A validade de constructo foi avaliada pela análise fatorial exploratória. O projeto foi aprovado pelos Comitês de Ética em Pesquisa do HCPA ( $\left.n^{\circ} 160580\right)$ e do GHC (no 17152). Na etapa de adaptação transcultural, após as considerações do comitê de especialistas e a aprovação do autor da ECPICID-AVC, a versão pré-teste foi avaliada em uma amostra de 30 cuidadores e os termos considerados de menor entendimento foram adequados. A versão final da Escala de Capacidades do Cuidador Informal de Idosos Dependentes por AVC (ECCIID-AVC) foi aplicada a 160 cuidadores, sendo 82,5\% mulheres com idade média de 49,6 $\pm 13,1$ anos. A análise fatorial sugeriu a exclusão de três itens e o agrupamento dos demais em seis domínios, explicando 70,52\% da variância total. Foram encontradas cargas fatoriais variando de 0,525 a 0,924. A consistência interna intra-avaliadores foi satisfatória, com coeficiente de correlação intraclasse de 0,94 (IC 95\%). A confiabilidade total foi considerada excelente (alfa Cronbach = $0,914)$. Considera-se a escala adaptada e válida para uso no contexto brasileiro para aplicação na prática clínica e na pesquisa.

palavras-chave

Cuidadores. Idoso. Estudos de Validação. Acidente Vascular Cerebral. Enfermagem. Psicometria.

DIAS, Lisiane Stefani. Prevalência de polineuropatia em mulheres pré e pós menopáusicas com obesidade grave sem diabetes: associações. Orientador: Helena Schimid. 2018. 105 f. il. color. Tese (Doutorado em Ciências da Saúde: Ginecologia 
e Obstetrícia) - Faculdade de Medicina, Universidade Federal do Rio Grande do Sul, Porto Alegre, 2018. Disponível em: http://hdl.handle.net/10183/188864. Acesso em: 27 abr. 2019.

\section{resumo}

Introdução: o Índice de Massa Corporal (IMC) e a prevalência de síndrome metabólica aumentam com o envelhecimento, especialmente no período pós-menopausa (PM). Em pacientes com obesidade severa (OS) (graus II e III) sem Diabetes Mellitus (DM) prevalência e associações de polineuropatia periférica (PNP) não estão bem caracterizadas. Objetivo: avaliar a prevalência de PNP de mulheres com OS, sem DM e buscar fatores independentemente associados a PNP. Métodos: um estudo transversal foi realizado em 450 mulheres OS. Foram submetidos ao Michigan Neuropathy Screening Instrument (MNSI) com PNP definido pelo ponto de corte $\geq 2,5$ e quatro sintomas, STOP-BANG Sleep Apnea Questionnaire (STOP-BANG) e a forma abreviada do Questionário Internacional de Atividade Física (IPAQ), assim como a medida de pressão arterial, IMC, circunferência da cintura, glicose sérica, hemoglobina glicada, LDL e HDL-colesterol, triglicerídeos, vitamina B12. Indivíduos com DM e aqueles com outras causas comuns de PNP foram excluídos. Para avaliar quais variáveis estavam independentemente associadas à PNP (variável dependente), foi utilizada a regressão do modelo de Poisson. Resultados: a prevalência de PNP foi de 11,6\%. Na análise univariada, PNP foi associada com idade, status de PM e diagnóstico de hipertensão arterial sistêmica ( $\mathrm{p}<0,001 ; \mathrm{p}<0,0001$; $p=0,016$, respectivamente) e houve uma tendência de associação com risco de apneia do sono $(\mathrm{p}=0,101)$. Na análise multivariada, apenas a idade ( $\mathrm{PP}=1,041$, IC95\% 1,012-1,072, $\mathrm{p}=0,006$ ) foi independentemente associada à presença de PNP ( $p<0,0001)$. Conclusão: A PNP em mulheres com OS sem diabetes não foi independentemente associado a estar no período PM, mas foi associado a maior idade. 
ESCHBERGER, Gabriela Gonçalves Kronbauer. Compreendendo o impacto das desigualdades sociais, econômicas e culturais na expectativa de vida de mulheres e de homens no mundo. Orientador: Aline Blaya Martins. 2017. 43 p. Dissertação (Mestrado em Saúde Coletiva) - Escola de Enfermagem, Universidade Federal do Rio Grande do Sul, Porto Alegre, 2017. (Texto não disponível on-line).

\section{resumo}

Introdução: o envelhecimento populacional tem sido cada vez mais explorado por estudiosos. As pesquisas demográficas e epidemiológicas trazem um envelhecimento acelerado e constante, no entanto, ainda são escassos os estudos que exploram as diferenças no que se refere ao impacto de tal processo sobre indicadores de expectativa de vida de mulheres e homens que vivem sob distintas condições socioeconômicas e culturais em nível mundial. Objetivo: o objetivo deste estudo foi avaliar e descrever o impacto de desigualdades socioeconômicas e culturais sobre os indicadores de expectativa de vida em mulheres e homens que vivem em diferentes países no mundo. Metodologia: trata-se de uma pesquisa epidemiológica observacional ecológica que utilizou banco de dados secundários da Organização Mundial de Saúde (OMS) e Organização das Nações Unidas (ONU) como fonte. Foram avaliadas e descritas as variáveis que compuseram os desfechos em estudo: médias de expectativa de vida ao nascer (EVN), saudável (EVS) e aos 60 anos (EV60) para mulheres e homens agrupados por países para o ano de 2015. As variáveis explicativas foram Índice de Desenvolvimento Humano (IDH), agrupamento dos países em Continentes e em distintos portes populacionais. Além disso, os desfechos também foram analisados em uma perspectiva de série histórica - ano de 2000 e 2015 - nos distintos continentes. Nesta análise foram avaliados quais os ganhos obtidos nos indicadores para mulheres e homens neste intervalo de 15 anos e quais as diferenças de ganhos entre mulheres e homens. Resultados: Há uma relação diretamente proporcional entre o Índice de Desenvolvimento Humano das nações e as expectativas de vidas tanto para mulheres quanto para homens, no entanto, observou-se que há uma diferença menor entre as expectativas de vida de mulheres e de homens quando estes vivem em países com menor Índice de Desenvolvimento Humano. Na análise de Continentes, a África teve ganhos maiores em 15 anos na expectativa de vida ao nascer de mulheres do que a dos homens no período estudado, sendo que no continente europeu os homens ganharam 1,41 anos a mais de Expectativa de vida ao nascer do que as mulheres no mesmo período. Quanto a expectativa de 
vida saudável observou-se que os homens parecem estar de uma forma geral apresentando mais ganhos no indicador do que as mulheres, exceto pelo continente africano. Após os 60 anos, a realidade dos indicadores se inverte em relação aos ganhos do continente africano, passando a ser este o continente com menores ganhos quando comparado com os demais países, porém, ainda assim, observa-se maiores ganhos para as mulheres do que para os homens. Realidade que não se observa no continente europeu. Na Europa, embora os homens ainda tenham valores absolutos de EV60 menores que as mulheres, estes apresentaram ganhos maiores em 15 anos do que as mulheres. Quanto aos portes populacionais não houve diferenças. Conclusão: é possível especular frente aos resultados obtidos neste estudo que fatores socioculturais e econômicos desempenhem impactos relevantes e diferentes sobre mulheres e homens ao longo do ciclo de vida e sugerem que as desigualdades entre os gêneros devam ser consideradas ao se implementar políticas que visem o envelhecimento ativo de mulheres e homens que vivem em distintos contextos, o que demonstra que a singularidade de envelhecer na África, sendo mulher, é muito distinta do envelhecimento dos homens na Europa e que tal aspecto precisa ser considerado na concepção e institucionalização de políticas públicas.

palavras - chave

Saúde. Envelhecimento da População. Desigualdade Social. Desigualdade de Gênero. Expectativa de Vida. Longevidade.

FARACO, Luciane Lovato. A hipótese da reparação civil por abandono afetivo do idoso que decorre da infração ao dever de cuidado. Orientador: Carlos Silveira Noronha. 2018. 105 f. Dissertação (Mestrado em Direito) - Faculdade de Direito, Universidade Federal do Rio Grande do Sul, Porto Alegre, 2018. Disponível em: http://hdl.handle.net/10183/181183. Acesso em: 27 abr. 2019.

resumo

Este trabalho versa sobre a hipótese de reparação civil por abandono afetivo que decorre da infração ao dever de cuidado do idoso. Analisa-se a tutela dos direitos dos idosos no ordenamento jurídico brasileiro através de um retrospecto legal com sutil referência ao contexto histórico mundial e ao Direito Comparado. Contextualiza-se a interpretação dos direitos dos idosos em face do fundamento do Direito pátrio na dignidade da pessoa humana 
a partir da Constituição Federal de 1988 e a transposição desta no Direito Civil e no Direito de Família. Adiante é apreciado o abandono afetivo, seu conceito e expansão pela a adoção do modelo atual eudemonista da família que importou na inclusão do dever de cuidado como elemento do afeto. A seguir o cuidado é abordado enquanto infração ao dever que dele decorre para identificação da conduta omissiva. Por fim, é explorado o instituto da responsabilidade civil, através do estudo de cada um dos seus requisitos, para conclusão quanto ao cabimento do dever de reparação pela constatação da ocorrência do ato ilícito de infração ao dever de cuidado que implica abandono afetivo em razão do dano que dele resulta e da extensão deste, isto valorado no caso concreto.

palavras-chave

Idoso. Dever de Cuidado. Abandono Afetivo. Dignidade Humana. Reparação (Direito).

FISCHER, Marcia Kraide. Treinamento muscular inspiratório na apneia obstrutiva do sono do idoso: ensaio clínico randomizado. Orientador: Denis Martinez. 2018. 166 f. Dissertação (Mestrado em Ciências Médicas) - Faculdade de Medicina, Universidade Federal do Rio Grande do Sul, Porto Alegre, 2018. Disponível em: http://hdl.handle.net/10183/188676. Acesso em: 27 abr. 2019.

resumo

Apneia obstrutiva do sono se caracteriza por repetidos episódios de obstrução, parcial ou completa, da via aérea superior durante o sono. A prevalência de apneia obstrutiva do sono aumenta com a idade fazendo dela um problema de saúde relevante aos idosos. O esforço respiratório repetitivo contra a via aérea obstruída e a hipóxia intermitente podem ter efeitos deletérios na musculatura inspiratória de pacientes com apneia obstrutiva do sono. O objetivo do estudo foi verificar o efeito do treinamento muscular inspiratório (TMI) sobre o Índice de Apneia-Hipopneia (IAH) em idosos com apneia obstrutiva do sono. Métodos: estudo randomizado em 34 idosos com diagnóstico de apneia obstrutiva do sono. Os pacientes elegíveis foram alocados aleatoriamente nos grupos TMI ou grupo sham-TMI. Os sujeitos do grupo TMI realizaram oito semanas de TMI consistindo de 30 inspirações máximas e 15 minutos de treinamento, duas vezes ao dia. A frequência da realização dos exercícios aumentou de três vezes por semana nas duas primeiras semanas, para cinco vezes na terceira e quarta semanas e diariamente nas quatro últimas semanas. 
A carga foi aumentada a cada duas semanas através da reavaliação da pressão inspiratória máxima (PIM) e do ajuste no dispositivo. Os participantes do grupo sham-TMI realizaram treinamento com a mesma frequência do grupo TMI sem carga no dispositivo. Todos os pacientes foram reavaliados com manovacuometria a cada duas semanas e refizeram os exames de polissonografia, ecografia, espirometria e manovacuometria após 8 semanas. Resultados: Os pacientes do grupo TMI completaram o protocolo com redução média no IAH de apenas 1,6 eventos/hora (intervalo de confiança-IC de95\% $-4,8$ a 1,6). No grupo TMI-sham, o IAH aumentou em 3,9 eventos por hora (IC 95\% 0,1 a 7,7). Foi observada interação significativa grupo $x$ tempo no modelo GEE para IAH $(\mathrm{P}=0,023)$ e para PIM $(\mathrm{P}<0,001)$. Não houve interação significativa grupo $\mathrm{x}$ tempo para pressão expiratória máxima $(\mathrm{P}=0,069)$, espirometria $(\mathrm{P}=0,075)$ e espessura do diafragma $(\mathrm{P}=0,176)$. Conclusão: Embora o TMI tenha sido eficaz em aumentar a PIM em idosos, a pequena redução no IAH obtida parece não ter utilidade clínica se a terapia por AOS for planejada.

\section{palavras-chave}

Apneia Obstrutiva. Sono. Idosos. Tratamento. Treinamento Muscular Inspiratório.

GIORDANI, Juliana Neves. Pressão arterial central e apneia obstrutiva do sono em idosos: estudo transversal. Orientador: Denis Martinez. 2018. 92 f. il. color. Dissertação (Mestrado em Ciências Médicas) - Faculdade de Medicina, Universidade Federal do Rio Grande do Sul, Porto Alegre, 2018. (Resumo e texto não disponíveis on-line).

palavras - chave

Apneia Obstrutiva do Sono. Idoso. Pressão Arterial. Estudos Transversais. Rigidez Vascular. Hipertensão.

GUADAGNIN, Eliane Celina. Mobilidade funcional em idosos: influência de parâmetros musculares e de treinamento. Orientador: Marco Aurelio Vaz. Co-Orientador: Felipe Pivetta Carpes. 2018. 97 f. il. Tese (Doutorado em Ciências do Movimento Humano) - Escola de Educação Física, Fisioterapia e Dança, Universidade Federal do Rio Grande do Sul, Porto Alegre, 2018. Disponível em: http://hdl.handle.net/10183/181830. Acesso em: 27 abr. 2019. 
A manutenção da qualidade de vida e da independência dos idosos está diretamente relacionada com a funcionalidade, a qual depende da estrutura e função do sistema musculoesquelético. Entender a relação entre parâmetros musculares e a funcionalidade em idosos possibilita delinear programas de treinamento adequados para prolongar a independência funcional dessa população. Nesse sentido, estudos mostram que o treinamento de força leva a ganhos de estrutura e função muscular, e de funcionalidade. Tarefas funcionais são realizadas utilizando diferentes tipos de contrações musculares. Porém, na literatura não há um consenso sobre a relação entre os parâmetros musculares e a funcionalidade em idosos, nem os efeitos de treinamentos de força utilizando diferentes tipos de contrações sobre a estrutura e função musculares, e a funcionalidade. Assim, o presente estudo teve como objetivos (1) identificar quais parâmetros estruturais e de função muscular de membros inferiores apresentam melhor relação e podem explicar o desempenho em tarefas funcionais; (2) revisar sistematicamente a literatura quanto aos efeitos de treinos com diferentes tipos de contrações para idosos; e (3) investigar os efeitos de um treinamento de força concêntrico versus um treinamento concêntrico-excêntrico para a musculatura flexora e extensora do joelho sobre parâmetros de estrutura e função muscular e funcionalidade de homens idosos. Para atingir esses objetivos, a presente tese foi dividida em quatro capítulos. No Capítulo 1 , verificou-se a relação entre parâmetros de estrutura e função muscular de membros inferiores (arquitetura muscular, eco intensidade e força isométrica) e parâmetros funcionais (testes Timed Up and Go e sentar-e-levantar, marcha no solo e marcha com transposição de obstáculo em velocidade preferida e máxima). No Capítulo 2, investigou-se parâmetros estruturais e de função muscular de flexores e extensores de joelho (torque isométrico, concêntrico e excêntrico, potência, taxa de produção de força, eco intensidade e arquitetura muscular), considerando, assim, além dos parâmetros investigados no Capítulo 1, parâmetros de força dinâmica e os relacionando com diferentes testes funcionais (sentar-e-levantar, Timed Up and Go, equilíbrio, velocidade de marcha, caminhada de seis minutos, subida e descida de degraus e salto vertical). Os principais achados desses estudos demonstram que a estrutura dos músculos vasto lateral e tibial anterior, e o torque concêntrico de extensores de joelho foram os parâmetros com melhor relação com a funcionalidade. Para verificar a influência do treino de força com diferentes tipos de contração sobre parâmetros de estrutura e função muscular e funcionalidade, no Capítulo 3 realizou-se uma revisão sistemática de estudos envolvendo treinamento de 
força isocinética para membros inferiores em idosos. Verificamos que tanto o treino de força concêntrico quanto o excêntrico apresentam efeitos positivos sobre a função muscular e a funcionalidade. Porém, a capacidade funcional foi investigada em apenas um estudo, e a estrutura muscular em nenhum deles. Além disso, nenhum dos estudos realizou um treino combinando diferentes tipos de contração, o que poderia ser mais benéfico para os idosos. Portanto, no Capítulo 4 são apresentados dados preliminares do estudo envolvendo treinamento de força para homens idosos, onde um grupo realizou treinamento exclusivamente concêntrico e outro treino concêntrico-excêntrico para flexores e extensores de joelho. Os indivíduos foram avaliados quanto aos mesmos parâmetros do Capítulo 2 em três momentos: basal, duas semanas após a avaliação basal e ao final do treinamento. Os dados preliminares demonstram que ambos os grupos de treino apresentaram ganhos tanto musculares quanto funcionais após o treinamento.

palavras-chave

Envelhecimento. Movimento Humano. Músculos. Treinamento de Força.

JAHN, Elisiane de Fátima. Envelhecimento, campesinato e o crédito consignado: o papel educativo de movimentos sociais em relação as estratégias de educação financeira com idosas camponesas e idosos camponeses. Orientador: Johannes Doll. 2018. 165 f. Tese (Doutorado em Educação) - Faculdade de Educação, Universidade Federal do Rio Grande do Sul, Porto Alegre, 2018. Disponível em: http://hdl.handle.net/10183/183230. Acesso em: 27 abr. 2019.

resumo

Esta tese de doutorado tem como tema de estudo o papel educativo dos Movimentos Sociais na vida de idosos camponeses e idosas camponesas, relacionando os campos de estudo campesinato, envelhecimento e crédito consignado. Possui como objetivos específicos: entender como o crédito consignado se relaciona com a vida de idosos e de idosas, pertencentes ao meio rural e que são integrantes de Movimentos Sociais; descrever as características do envelhecimento camponês, a partir de revisão bibliográfica, entrevistas, e observação participante realizada durante a pesquisa; identificar, a partir das falas de idosos e de idosas, bem como das lideranças locais, a importância dos Movimentos Sociais Sociais em relação as estratégias de educação financeira, o 
campesinato e o envelhecimento. A pesquisa participante foi realizada com 19 pessoas idosas dos municípios de Sagrada Família, Lajeado do Bugre, Ibirubá e Selbach, no Rio Grande do Sul. Juntamente ao trabalho com os camponeses e as camponesas, realizei entrevistas com 3 (três) lideranças locais do Movimento de Mulheres Camponesas e do Movimento dos Pequenos Agricultores. As entrevistas foram realizadas com pessoas entre 58 e 85 anos, sendo 15 (quinze) mulheres e 4 (quatro) homens. Apenas uma das pessoas idosas entrevistadas não havia participado de nenhuma atividade dos Movimentos Sociais citados, mas ela os conhecia e reconhecia sua importância para os sujeitos do campo. Para tanto, se procurou aproximar as compreensões sobre campesinato, envelhecimento, crédito consignado (que é apenas uma ação na vida financeira das pessoas) e movimentos sociais. Essa perspectiva permitiu um enlace de temas ainda pouco explorados, quando pensados em sua forma articulada. De resultados temos, além da construção teórica sobre campesinato, envelhecimento e crédito consignado, a percepção dos sujeitos entrevistados sobre tais assuntos, de modo a dar voz e visibilidade àqueles e àquelas que vivenciam essas questões no seu cotidiano. Com relação ao papel educativo dos Movimentos Sociais, percebemos o quanto o ato de movimentar-se muda as pessoas, que aprendem e de forma coletiva passam a ressignificar seus conhecimentos e suas práticas. As principais referências teóricas utilizadas para o campesinato foram: Wanderley (2009); Ploeg (2008); Carvalho (2005); Cardoso (1987); Via Campesina (2013); Chayanov (2016); Shanin (1980); Ploeg (2016); Conte (2014). Para discutir teoricamente o envelhecimento foram utilizados: Netto (2002); Camarano e Pasinato (2006); IBGE; Silva (2008); Debert (1999/1996); Gorz (2009); Doll (2012); Minayo (2003). Com relação ao envelhecimento do campo: Wanderley e Favareto (2013); Camarano e Abramovay (2009); Morais, Rodrigues e Gerhardt (2008). Para o aprofundamento sobre o crédito consignado, foram citados: Doll e Cavallazzi (2016); Bauman (2008); Palácios (2008); SPC (2014). Por último, com relação a Movimentos Sociais, Rinco e Domingues (2012), contribuíram para o aprofundamento teórico.

palavras-chave

Aprendizagem Cooperativa. Campesinato. Educação Financeira. Envelhecimento. Idoso. Movimentos Sociais. Mulher. 
ALVAREZ, Pamela Francisca Jorquera. Etnografia da duração sobre o processo de envelhecimento e a vivência da velhice em Inca de Oro, Chile. Orientador: Cornelia Eckert. 2017. 148 f. il. Tese (Doutorado em Antropologia Social) - Instituto de Filosofia e Ciências Humanas, Universidade Federal do Rio Grande do Sul, Porto Alegre, 2017. Disponível em: http://hdl.handle.net/10183/169011. Acesso em: 28 abr. 2019.

\section{resumo}

Mundialmente, assistimos ao crescente envelhecimento populacional. As projeções para a América Latina indicam que para o ano 2050 uma em cada quatro pessoas será idosa (CAIRE, 2013). O Chile compartilha esta tendência mundial, fazendo parte dos quatro países mais envelhecidos da América Latina que incluem Argentina, Cuba e Uruguai. Esse contexto impõe desafios aos diferentes países, e a discussão dos aspectos sociais, econômicos, de bem-estar e previdência social é imperativa. A Antropologia discute sobre o envelhecimento e a velhice nas sociedades contemporâneas, problematizando a necessidade de desconstrução de certas abordagens e considerando a heterogeneidade desse processo. A evidência demográfica é uma característica própria desse fenômeno na atualidade, estudá-la envolve não cair em um determinismo demográfico nem biológico, abrindo a discussão sobre as condições sociais e culturais de sua expressão na sociedade contemporânea (GUILLEMARD, 2005). Através da Etnografia da duração (ECKERT; ROCHA, 2011) a tese dá conta das multiplicidades de estilos de vida e de tempos se passando em uma pequena cidade (BOZON, 1984) mineradora, localizada no Norte do Chile, Inca de Oro. Para compreender o processo de envelhecimento e a vivência da velhice, a tese objetiva o estudo do tempo através das narrativas dos idosos e das idosas do vilarejo, visando a análise mediante o estudo da memória (HALBWACHS, 2011). Também discute as questões do corpo, pois é nele que se evidencia a passagem do tempo (FASSIN, 2007). Envelhecer e experienciar a velhice em Inca de Oro adquire particularidades próprias que surgem, mantêm-se e enquadram-se sob o abrigo da estrutura social do povoado, estrutura demarcada pela pirquineria - mineração artesanal de exploração de ouro, e pela presença de valores provenientes das sociedades industriais e sociedades indígenas andinas. No entanto, a pesquisa também mostra como, dentro dos limites sociais aceitos e das normatividades de gênero e idade imperantes no povoado, os idosos e as idosas - interlocutores desta pesquisa - negociam sua realidade (VELHO, 2013), servindo-se de diferentes agenciamentos em sua vida cotidiana (DAS apud ORTEGA, 2008). 
palavras-chave

Antropologia Social. Chile: Aspectos Sociais. Cidade. Corpo. Etnografia de Duração. Revitalização Urbana. Transformações Urbanas. Velhice.

KRAUSE, Josianne da Costa Rodrigues. A dança como estratégia de promoção da saúde cardiometabólica e independência funcional no envelhecimento. Orientador: Álvaro Reischak de Oliveira. 2018. 86 f. il. Tese (Doutorado em Ciências do Movimento Humano) - Escola de Educação Física, Fisioterapia e Dança, Universidade Federal do Rio Grande do Sul, Porto Alegre, 2018. Disponível em: http://hdl.handle.net/10183/188444. Acesso em: 28 abr. 2019.

\section{resumo}

Introdução: o envelhecimento biológico é caracterizado, dentre outros fatores, por uma diminuição de massa muscular concomitante a um aumento de tecido adiposo visceral, elevando o risco do desenvolvimento de doenças cardiovasculares e dependência física. A dança tem sido sugerida como uma intervenção de exercício potencial para melhorias cardiometabólicas e funcionais com o envelhecimento. Além disso, é uma atividade amplamente praticada pelos idosos como lazer, sendo uma intervenção de baixo custo e grande aderência por essa população. Entretanto, conclusões acerca dos efeitos da dança como forma de exercício para saúde ainda são limitadas, principalmente devido à falta de comparação com outros tipos de exercício físico, bem como ao número limitado de ensaios clínicos randomizados controlados analisando marcadores de risco cardiovascular (RCV). Objetivo geral: verificar os efeitos de uma intervenção de dança, comparada a um exercício aeróbio tradicional (caminhada) e a um grupo controle (alongamento), sobre marcadores RCV e capacidade funcional de mulheres idosas, em um ensaio clínico randomizado controlado (ECRc). Adicionalmente, verificar as respostas cardiorrespiratórias agudas de uma aula de dança para idosas, em um estudo de respostas agudas (antes e depois). MÉTODOS: Trinta mulheres sedentárias ( $65 \pm 5$ anos, índice de massa corporal (IMC) $27 \pm 4$ ) foram randomizadas em três grupos de intervenção ( $n=10 /$ grupo): dança, caminhada e alongamento (controle ativo) com duração de oito semanas (grupos dança ou caminhada 3x/sem, 60min; grupo alongamento $1 \mathrm{x} / \mathrm{sem}, 60 \mathrm{~min})$. Intervenções: Dança: elementos técnicos (ballet, jazz, etc.), estilos variados (danças latinas, dança aeróbica, etc), sem par. Caminhada: esteira, intensidade 60\% VO2pico. Alongamento: grandes 
grupos musculares, sem desconforto. Intervenções incluíam aquecimento, parte principal (35-40 min), e volta à calma. Foram avaliados no período pré e pós intervenção: consumo de oxigênio de pico (VO2pico, desfecho primário); insulina, CRP, TNF- $\alpha$, circunferências da cintura e quadril, tecido adiposo visceral, colesterol total, HDL-C, LDL-C, glicose, espessura muscular do quadríceps, força máxima e potência muscular, equilíbrio estático e dinâmico, marcha, flexibilidade, habilidade de sentar e levantar, e nível de atividade física. Os resultados estão descritos em média e IC (95\%). As comparações intra e entre grupos foram realizadas pelo método de Equações de Estimativas Generalizadas, post hoc LSD ( $p<0,05)$, utilizando o software SPSS 22.0 Tamanho de efeito (TE) da intervenção de dança vs. alongamento (D vs. A) e caminhada vs. alongamento ( $\mathrm{C}$ vs. A) também foram calculados. Resultados: ECRc (pré vs. pós): efeito de interação grupo vs. tempo mostrou aumentos no $\mathrm{VO} 2$ pico (mL.kg-1.min-1) após a intervenção de dança 23,3 (20,8-25,8) vs. 25,6 (23,4-27,8), e caminhada $23,4(21,3-25,5)$ vs. $27,0(25,4-28,6)$, sem diferenças no grupo alongamento $23,5(21,3-25,7)$ vs. 23,0 (21-24,9). Não houve diferença entre os grupos dança e caminhada. O grupo caminhada foi superior ao grupo alongamento no momento pós-intervenção. TE: $\mathrm{D}$ vs. $\mathrm{A}=0,72, \mathrm{C}$ vs. $\mathrm{A}=1,28$. Altura do salto vertical $(\mathrm{cm})$ também melhorou para os grupos dança 11,2 (9,3-13,1) vs. 12,2 (10,3-14), e caminhada 10,3 (9-11,6) vs. 11,3 (9,7-13), sem diferença para o grupo alongamento $9,8(8,6$ to 11,3$)$ vs 9,3 (7,8 to 10,7$)$. Não houve diferença entre os grupos dança e caminhada. O grupo dança foi superior ao grupo alongamento no momento pós-intervenção. TE: $D$ vs. $A=1,00, C$ vs. $A=0,74$. Equilíbrio estático (s) também melhorou para os grupos dança 5,44 (2,34-8,55) vs 11,07 (6,53-15,62) e caminhada $5,67(2,91-8,42)$ vs. $14,46(9,09-19,84)$, sem diferença para o grupo alongamento $4,05(2,28-5,82)$ vs. $4,04(3,12-4,97)$. Não houve diferença entre os grupos dança e caminhada. Ambos os grupos dança e caminhada foram superiores ao grupo alongamento no momento pós-intervenção. TE: $\mathrm{D}$ vs. $\mathrm{A}=$ 1,22 , C vs. A = 1,55. Habilidade de marcha e equilíbrio dinâmico melhoraram apenas para o grupo caminhada. Efeito tempo (efeitos agrupados) mostrou melhoras em relação aos marcadores inflamatórios CRP (mg/L)1,65 (1,56-1,73) vs. $1,55(1,44-1,65)$ e TNF $\alpha$ (pg/mL) 6,69 (6,36-7,02) vs. 6,04 (5,82-6,25), LDL-C (mg/dL) 139,1 (126,6-151,7) vs. 130,7 (117,1-144,4), HDL-C (mg/dL) 43,3 (38,9-47,7) vs. 47,4 (42,6-52,3), gordura visceral (mm) $48,1(40,1-56,0)$ vs. $42,9(35,9-50,0)$, habilidade de sentar e levantar (s) 10,23 (9,71-10,75) vs. 8,32 (7,88-8,76), flexibilidade (cm) -0,60 (-2,44-1,24) vs. 1,71 (-0,51-3,92), e nível de atividade física (tempo de caminhada em min.semana) 85 (39-131) vs. 233 (154-313). Não foram encontradas diferenças para perfil glicêmico, triglicerídeos, colesterol total, força e espessura muscular do quadríceps. Estudo de respostas agudas $(\mathrm{n}=10$ 
participantes do grupo dança, resultados em média \pm desvio padrão): Teste de esforço máximo: VO2 (mL.kg-1. min-1): VO2pico $(23,3 \pm 4,3)$, primeiro limiar ventilatório $(\mathrm{LV} 1)(17,2 \pm 3,5)$ e segundo limiar ventilatório $(20,9 \pm 3,4)$. Aula de dança; VO2 (mL.kg-1. min-1, \%VO2pico): aquecimento (12,8 $\pm 2,4,55 \%)$, deslocamento (14,2 $\pm 2,4,62 \%)$, coreografia $(14,6 \pm 3,2,63 \%)$ e show $(16,1 \pm 3,3,69 \%)$. A parte do show (coreografia aprendida) foi igual ao LV1 das participantes. Conclusões: Os resultados do ECRc mostraram que a intervenção de dança foi capaz de induzir ganhos cardiorrespiratórios, potência de membros inferiores e equilíbrio estático iguais à caminhada, enquanto o grupo alongamento não apresentou mudanças. Ganhos adicionais em marcha e equilíbrio dinâmico foram verificados após a intervenção de caminhada. O engajamento em quaisquer das intervenções (alongamento, dança ou caminhada) foi capaz de atenuar marcadores inflamatórios e perfil lipídico, bem como induzir mudanças positivas na composição corporal. Os resultados do estudo de respostas cardiorrespiratórias agudas mostraram que a aula de dança elaborada para idosas foi de baixa intensidade aeróbia (LV1).

palavras-chave

Caminhada. Capacidade Funcional. Condicionamento Físico Humano. Dança. Envelhecimento. Exercício Aeróbico.

LOCATELLI, Patrícia Augusta Pospichil Chaves. A relação do idoso com o trabalho: uma proposta de compreensão à luz da teoria das representações sociais. Orientador: Elaine di Diego Antunes. 2018. 212 f. il. Tese (Doutorado em Administração) - Escola de Administração, Universidade Federal do Rio Grande do Sul, Porto Alegre, 2018. Disponível em: http://hdl.handle.net/10183/189865. Acesso em: 28 abr. 2019.

\section{resumo}

Esta tese apresenta o resultado de uma investigação que entrecruzou os temas envelhecimento e trabalho à luz da teoria das Representações Sociais. Partindo-se do entendimento de que a forma como os indivíduos pensam e agem é determinada pelo social e de que a relação que os idosos estabelecem com o seu trabalho está diretamente vinculada e pode ser mais bem compreendida a partir da interpretação das representações sociais por eles elaboradas, este estudo objetivou compreender como as representações sociais de trabalhadores idosos permeiam sua relação com o trabalho. O percurso metodológico partiu de uma perspectiva interpretativista, sendo este um 
estudo qualitativo. A coleta de dados foi conduzida de acordo com os pressupostos da metodologia narrativa, operacionalizada por meio de entrevistas narrativas biográficas e notas de campo. O corpus da pesquisa foi formado por seis idosos trabalhadores do meio urbano - com 60 anos ou mais e distintas ocupações. Os resultados deste estudo apontaram para a variabilidade das representações sociais. No que tange especificamente à fase de vida atual, foram identificadas seis distintas representações sobre o trabalho: "atividade", "meio", "segurança", "missão", "dom" e "obrigação". Todavia, em alguns casos constatou-se a coexistência e o atravessamento de representações oriundas de outras etapas de vida, o que diverge da ideia de que o surgimento de novas representações resultaria na eliminação das mais antigas. A função das representações sociais, como norteadoras da conduta dos indivíduos foi evidenciada em todos os casos apresentados. A análise das trajetórias de vida e de trabalho dos idosos revelou como elas foram transpassadas pelas representações dos entrevistados. De igual modo, as representações influenciam no comportamento dos indivíduos, na tomada de decisões e, consequentemente, em sua relação com o trabalho, inclusive no que se refere a planos futuros. No que tange ao envelhecimento, as percepções dos entrevistados perpassaram duas perspectivas divergentes de velhice, uma com foco nas perdas e outra com foco nos ganhos. A associação entre aposentadoria e envelhecimento esteve presente nas narrativas dos entrevistados, principalmente no que se refere às perdas decorrentes do processo de envelhecimento - físicas, sociais, profissionais e financeiras. Na opinião deles, a velhice não deve representar um período de ociosidade. Destacou-se entre os idosos a menção a planos futuros e o desejo pela continuidade da realização de atividades produtivas. De modo geral, a relação dos idosos com o trabalho está pautada pela realização e satisfação que o desempenho da atividade pode oferecer, além da possibilidade de ocupação do tempo e da mente.

palavras-chave

Envelhecimento. Idoso. Representações Sociais. Trabalho.

MARQUES, Fernanda Pasquetti. Atenção domiciliar ao idoso no contexto das equipes da atenção básica no município de Porto Alegre/RS: a perspectiva do profissional. Orientador: Alexandre Fávero Bulgarelli. 2018. 76 f. il. Dissertação (Mestrado em Saúde Coletiva) - Escola de Enfermagem, Universidade Federal do Rio Grande do Sul, Porto Alegre, 2018. (Texto não disponível on-line). 
Introdução: há, na atualidade, um aumento no contingente de idosos. No Brasil, esse processo está se dando de forma rápida. Em concomitância, tem-se no país um sistema de saúde em que a Atenção Básica é a responsável pela criação do vínculo com o usuário e pela integralidade e longitudinalidade do cuidado e da atenção. A demanda por serviços de Atenção Domiciliar (AD) por usuários idosos impossibilitados de acessar as Unidades de Saúde e/ou acamados é uma conjuntura que enseja discussões. Objetivos: a presente pesquisa tem por objetivo compreender a Atenção Domiciliar ao idoso, realizada na Atenção Básica, sob a perspectiva dos profissionais da saúde (médicos, enfermeiros e cirurgiões-dentistas) do distrito docente-assistencial da Universidade Federal do Rio Grande do Sul: Gerência Distrital Glória Cruzeiro Cristal, localizado no município de Porto Alegre. Metodologia: trata-se de um estudo de abordagem teórico-metodológica qualitativo, com desenho de pesquisa compreensivista, em que foram trabalhadas as percepções dos sujeitos participantes referente ao processo de acontecimentos dos atendimentos domiciliares. Em um primeiro momento, foram levantados dados sobre o contexto dos profissionais, bem como a história e a dinâmica da $\mathrm{AD}$ realizada no cenário do estudo. Levantaram-se, também, elementos provenientes dos contextos políticos e sociais deste modelo de atenção relacionando a realidade do município de Porto Alegre, especificamente do distrito docente-assistencial. No segundo momento, os dados foram coletados por meio de entrevistas semidirigidas e após as transcrições os dados foram sistematizados e analisados segundo a Análise de Conteúdo, a partir de uma Análise Temática. Durante o terceiro momento, optou-se pela interpretação das categorias com o suporte teórico do referencial hermenêutico-dialético. Realizou-se a análise do consenso das percepções articulando-as com os contrastes referentes ao olhar para o dissenso, permitindo-se, desse modo, a construção da interpretação das categorias. Interpretação e discussão das informações: foram sistematizadas três categorias de análise que são elas: a realidade do território e as possibilidades de cuidado dentro do domicílio; a integralidade da atenção enquanto ferramenta para efetivação da Atenção Domiciliar na Atenção Básica; o fluxo do serviço que propicia a rotina organizacional das visitas domiciliares aos idosos. Conclusão: acredita-se que os resultados dessa pesquisa contribuam para o desenvolvimento do modelo assistencial da Estratégia de Saúde da Família do município, e impulsionem a elaboração de novas pesquisas sobre este tema tão importante para o cuidado de idosos. Além de valorizar ações da Atenção Domiciliar na Atenção Básica, reconhecendo o esforço dos profissionais que realizam de modo rotineiro essa modalidade de atenção à saúde. 
Saúde do Idoso. Assistência Domiciliar. Atenção à Saúde. Sistema Único de Saúde: Porto Alegre/RS.

MEIRELES, Louisiana Carolina Ferreira de. Modificações epigenéticas hipocampais em histonas induzidas pelo envelhecimento e por diferentes modalidades de exercício físico: impacto sobre a memória aversiva. Orientador: Ionara Rodrigues Siqueira. 2018. 102 f. il. Tese (Doutorado em Fisiologia) - Instituto de Ciências Básicas da Saúde, Universidade Federal do Rio Grande do Sul, Porto Alegre, 2018. Disponível em: http://hdl.handle.net/10183/180214. Acesso em: 28 abr. 2019.

\section{resumo}

O objetivo dessa tese foi estudar o impacto de diferentes modalidades de exercício físico sobre a memória aversiva e marcas epigenéticas em histonas globais e em região promotora de genes de interesse no hipocampo de ratos Wistar durante o processo de envelhecimento. Para isso, foram realizados dois experimentos. No primeiro, investigamos o efeito de um protocolo de exercício aeróbico 20 minutos, diariamente durante 2 semanas, sobre a memória aversiva e níveis de acetilação da H3K9, H4K12 e H4K5 em hipocampo de ratos Wistar adultos jovens e envelhecidos. Este protocolo de exercício, melhorou a memória aversiva e aumentou os níveis de acetilação da H4K12 em ambas as idades testadas. O exercício também foi capaz de aumentar os níveis de acetilação da H3K9 em ratos envelhecidos. Além disso, foi observado um declínio cognitivo relacionado ao envelhecimento sem qualquer efeito no estado de acetilação de histonas. No segundo experimento, ratos adultos jovens e envelhecidos foram submetidos a 12 semanas de treinamento físico nas modalidades aeróbica, força, acrobática ou combinada. Nesses animais foi investigado o efeito do envelhecimento e do exercício na memória e em marcadores epigenéticos na região promotora dos genes cFos, Bdnf e Dnmt3a em hipocampo. O envelhecimento foi associado a modificações epigenéticas em histonas nos promotores de Bdnf, cFos e Dnmt3a. As modalidades aeróbica, acrobática e combinada melhoraram o desempenho na memória aversiva em ambas as idades testadas. Além disso, essas modalidades alteraram a acetilação da H3K9 e trimetilação da H3K4 no promotor do cFos de animais envelhecidos. As modalidades aeróbica e força reverteram parcialmente os aumentos induzidos pela idade na trimetilação da $\mathrm{H} 3 \mathrm{~K} 4$ no promotor do Bdnf. O treino de força e a combinação de modalidades alteraram a acetilação da H4K8 no promotor do Dnmt3a em ratos adultos jovens. Em suma, nossos resultados 
demonstraram que o exercício físico melhora a memória aversiva de ratos Wistar, de maneira protocolo-dependente, sendo efetivas as modalidades aeróbica, acrobática e combinada. Além disso, um importante achado desse trabalho foram as mudanças relacionadas ao envelhecimento e ao exercício físico em marcas epigenéticas, tanto em histonas específicas quanto em região promotora de genes de interesse no hipocampo de ratos Wistar. Nossos resultados contribuem para a literatura, fornecendo possíveis mecanismos biológicos que sustentem a prescrição clínica de diferentes modalidades de exercício para atenuar os déficits de memória durante o envelhecimento.

palavras-chave

Envelhecimento. Epigenômica. Exercício. Hipocampo. Histonas. Memória. Teste de Esforço.

MENDES, Jozelina Silva da Silva. Educação intergeracional a distância: conect@ndo jovens e idosos. Orientador: Patrícia Alejandra Behar. 2018. 144 f. Dissertação (Mestrado em Educação) - Faculdade de Educação, Universidade Federal do Rio Grande do Sul, Porto Alegre, 2018. Disponível em: http://hdl.handle. net/10183/181835. Acesso em: 26 abr. 2019.

\section{resumo}

A presente pesquisa tem por objetivo investigar quais ações educativas intergeracionais podem contribuir para aproximar jovens e idosos na Educação Intergeracional a Distância. O envelhecimento da população mundial evidencia a necessidade de aumentar a participação social e a educação ao longo da vida para propiciar um envelhecimento mais saudável. Além disso, o aumento do consumo das tecnologias por idosos apontam para uma oportunidade de inclusão digital. Nessa perspectiva, a Educação a Distância (EAD) pode se constituir em uma alternativa para o público idoso, incluindo-o na sociedade e aproximando-o ainda mais de outras gerações através da Educação Intergeracional (EI). Países como Estados Unidos, Portugal, Espanha e Brasil vem ofertando atividades intergeracionais envolvendo jovens e idosos. Contudo, tais iniciativas ocorrem em contextos de educação presencial, ocasionando por vezes uma dificuldade em conciliar a disponibilidade dos envolvidos, conforme relatado por Patrício (2014). Sendo assim, a presente pesquisa objetiva investigar quais ações educativas intergeracionais podem contribuir para aproximar jovens e idosos na Educação Intergeracional a Distância. A metodologia adotada foi análise quali-quantitativa, do tipo estudo de casos múltiplos. Para coleta de dados, utilizou-se questionários semiestruturados, 
entrevistas abertas, observação participante, mapa social (uma ferramenta que analisa as interações dentro do ambiente virtual) e interações em grupos no WhatsApp. O público-alvo foi 24 idosos com 60 anos ou mais, que participam de um curso de inclusão digital na Unidade de Inclusão Digital (UNIDI) da UFRGS. Além destes, também participaram 5 jovens com idade entre 15 a 29 anos. Os dados coletados apontaram que ambos os públicos possuem um perfil semelhante no que se refere ao uso das tecnologias para a interação a distância. No entanto, mesmo sabendo utilizar as ferramentas e tendo acesso a esses recursos de comunicação alguns idosos não se comunicaram com os jovens. Tal constatação evidencia a necessidade de se pensar em estratégias pedagógicas que auxiliem os idosos a interagirem à distância. A análise das trocas entre jovens e idosos possibilitou o mapeamento de 11 ações educativas intergeracionais que podem ser utilizadas na Educação Intergeracional a Distância, com vistas a aproximar jovens e idosos e apontou ainda para a necessidade de ampliação dos estudos nessa área.

\section{palavras - chave}

Educação a Distância. Educação de Jovens e Adultos. Idoso. Tecnologia Educacional.

MULLER, Carlos Henrique de Lemos. Resposta ao choque térmico e da razão HSPA1A extra/intracelular em leucócitos de indivíduos idosos e de meia idade submetidos a treinamento de força. Orientador: Maurício da Silva Krause. 2018. 73 f. il. Dissertação (Mestrado em Fisiologia) - Instituto de Ciências Básicas da Saúde, Universidade Federal do Rio Grande do Sul, Porto Alegre, 2018. Disponível em: http://hdl.handle.net/10183/174954. Acesso em: 28 abr. 2019.

\section{resumo}

Justificativa: o processo de envelhecimento está associado com o aumento demasiado na produção das espécies reativas de oxigênio (EROS). Dentre as estratégias que as células desenvolveram ao longo da evolução para combater o estresse celular, destacam-se as proteínas de choque térmico (HSP). Em especial, a HSPA1A (HSP72) é importante para recuperação de proteínas danificadas, impedindo a agregação das mesmas no citoplasma. O processo de envelhecimento parece estar associado a um declínio nos níveis das HSPs, resultando na perda do controle da proteostase, atrofia muscular, resistência à insulina e incapacidade de reparo após dano. Já é demonstrado na literatura que o exercício físico aumenta a expressão de HSPA1A, o que, possivelmente, exerce função protetora durante o envelhecimento e reduz a 
inflamação sistêmica clássica encontrada em idosos. Mais recentemente, tem se verificado que HSPA1A pode ser encontrada tanto dentro quanto fora das células, apresentando funções diferentes. Intracelularmente (iHSP70), apresenta função protetora, anti-inflamatória e anti-apoptótica, enquanto que no meio extracelular (eHSP70) apresenta um importante papel imunológico, com função pró-inflamatória e pró-apoptótica. Objetivos: a presente dissertação esta dividida em três partes distintas, denominados como estudos 1, 2 e 3 . No primeiro estudo, o objetivo foi comparar a resposta ao choque térmico (leucócitos expostos a temperatura elevada $-42^{\circ} \mathrm{C}$ por 2 horas) em diferentes populações: indivíduos de meia-idade, idosos e idosos com diabetes do tipo 2. No segundo estudo, o objetivo foi verificar a influência de um protocolo de treinamento de força na relação da HSPA1A extra e intracelular em leucócitos, do dano oxidativo, das adaptações neuromusculares e morfológicas, em indivíduos de meia-idade Finalmente, no último estudo, serão mostrados dados preliminares da resposta de indivíduos idosos ao mesmo protocolo e parâmetros do estudo dois. Metodologia: no primeiro estudo os voluntários foram divididos em três grupos: Meia Idade (49,36 $\pm 3,61$ anos), Idosos (63,57 $\pm 3,25$ anos) e Idosos Diabéticos (68,9 \pm 7,8 anos; HbA1c $7 \pm 0,67 \%$ ). Foram realizadas coletas de sangue para posterior indução ao choque térmico e avaliação da eHSP70. Nos estudos dois e três, indivíduos de meia-idade (40-59 anos) e idosos (60-75 anos), respectivamente, foram randomicamente alocados nos grupos Controle ou Treinado. O treinamento durou doze semanas com frequência de três vezes por semana. Cada sessão de treinamento incluía nove exercícios de força tanto para membros inferiores quanto superiores e três exercícios funcionais (subir um lance de escadas, sentar e levantar e subir e descer de uma caixa). Antes e após esse período foram realizadas coletas de sangue para posterior análise da HSPA1A extracelular e intracelular em leucócitos, avaliação de peroxidação lipídica (TBARS), atividade antioxidante (SOD e CAT), nitritos e do perfil lipídico. Foram realizadas avaliações de composição corporal, força e teste de consumo máximo de oxigênio Resultados: A resposta ao choque térmico (avaliada pela capacidade das células em exportar eHSP70 quando submetidas a uma temperatura elevada) parece ser igual entre indivíduos de meia-idade e idosos saudáveis. Curiosamente, em indivíduos idosos e com diabetes, esta resposta parece estar bloqueada, indicando que a resistência à insulina e o diabetes tem um papel dominante na capacidade da resposta ao estresse. Quando indivíduos de meia-idade (estudo 2) foram submetidos ao treinamento de força, os mesmos responderam com ganhos de força, melhora da capacidade funcional e aumentos na massa muscular. No entanto, a resposta ao choque térmico (eHSP70 e iHSP70) não foi modificada 
pelo treinamento, possivelmente pelo fato de que esta se encontrava normal. Os dados preliminares do estudo 3 mostram que, em idosos saudáveis, ocorreram ganhos de força, melhora da capacidade funcional, redução do tecido adiposo visceral (VAT) e melhora da resposta ao choque térmico após o treinamento, no entanto, considerando o baixo $\mathrm{n}$ amostral, essa resposta ainda deve ser confirmada em estudos posteriores Conclusão: a ausência de resposta ao choque térmico em Diabéticos está relacionada com resistência à insulina e inflamação, de modo que o treinamento de força parece ser uma alternativa eficaz para contornar esse quadro. Em relação ao efeito do treinamento, em sujeitos de Meia Idade, ele mostra-se eficaz para reduzir as chances de sarcopenia e dinapenia e possíveis doenças relacionadas ao processo do envelhecimento. Os dados preliminares em idosos saudáveis demonstram que, além de diminuir as chances de sarcopenia e dinapenia, o treinamento parece eficaz para reduzir inflamação sistêmica, visto que houve redução do VAT e aumento da resposta ao choque pós-treinamento. Este projeto é financiado pelo CNPq, Edital Universal (Processo oㅜ 482398/2013-2).

\section{palavras-chave}

Diabetes Mellitus. Envelhecimento. Estresse Oxidativo. Exercício. Leucócitos. Proteínas de Choque Térmico HSP72.

PARISI, Mariana Migliorini. Impacto da obesidade sobre células do sistema imune: instabilidade genômica, disfunção mitocondrial, imunossenescência e ativação inflamatória. Orientador: Florencia María Barbé-Tuana. Co-Orientador: Fátima Theresinha Costa Rodrigues Guma. 2018. 135 f. il. Tese (Doutorado em Bioquímica) - Instituto de Ciências Básicas da Saúde, Universidade Federal do Rio Grande do Sul, Porto Alegre, 2018. Disponível em: http://hdl.handle. net/10183/180237. Acesso em: 28 abr. 2019.

resumo

A imunossenescência é caracterizada pelo declínio funcional do sistema imune. Envolve mudanças fenotípicas que se traduzem em alterações sistêmicas, tendo importante impacto na sua funcionalidade. A imunossenescência tem sido associada a evolução e desfecho clínico de muitas doenças associadas ao envelhecimento prematuro, como a obesidade. A obesidade é uma condição patológica associada a expansão do tecido adiposo e a uma inflamação crônica 
de baixo grau que exerce efeitos negativos em múltiplos tecidos. Evidências de senescência celular, como atividade da enzima beta galactosidase ( $\beta$-gal) aumentada, presença de fenótipo secretor associado a senescência e a expressão aumentada da proteína supressora de tumor TP53 (p53) e CDKN1A (p21) tem sido descritas no tecido adiposo de indivíduos portadores de obesidade. No entanto, é pouco explorado na literatura como esta inflamação sistêmica pode impactar no possível envelhecimento prematuro do sistema imune em indivíduos portadores de obesidade. Assim, o objetivo desta tese foi avaliar alterações associadas a imunossenescência prematura em células mononucleares de sangue periférico (PBMC) expostas ao ambiente pró-inflamatório próprio da obesidade. Para isto, foram utilizadas três abordagens experimentais: (1) análise de parâmetros associados a imunossenescência prematura em PBMC saudáveis incubadas com plasma de indivíduos portadores de obesidade; (2) análise de parâmetros de imunossenescência em macrófagos diferenciados a partir da linhagem celular U-937 e incubados com plasma de indivíduos portadores de obesidade sem comorbidades ou com síndrome metabólica; e (3) validação dos parâmetros de imunossenescência em PBMC de indivíduos portadores de obesidade. Nossos resultados mostraram que o plasma de indivíduos portadores de obesidade é capaz de modular o fenótipo de PBMC previamente saudáveis, induzindo aumento na morte celular por apoptose, sinalização comprometida de H2AFX e TP53, disfunção mitocondrial basal e associada a produção de ATP, aumento de linfócitos senescentes T auxiliares CD4+CD28- e citotóxicos CD8+CD28-, secreção de citocinas inflamatórias e ativação de monócitos e macrófagos. Além disso, o plasma de indivíduos portadores de obesidade, independente da presença de comorbidades, induziu aumento da atividade da enzima $\beta$-gal associada com a diminuição da viabilidade de macrófagos, aumentando sua capacidade fagocítica. Parte destes dados foram confirmados em PBMC de indivíduos portadores de obesidade, mostrando aumento da taxa de morte celular por apoptose, instabilidade genômica através de uma cinética de reparo de dano ao DNA comprometida, menor sinalização de H2AFX e aumento na frequência de micronúcleos e cariólise. Ainda, foi confirmada a redução da sinalização da via TP53/CDKN2A (p53/p16) e de ERK1/2 e o aumento na secreção de citocinas inflamatórias. Juntos, nossos dados confirmam a hipótese da obesidade como uma patologia associada a imunossenescência prematura e instabilidade genômica.

palavras-chave

Dano ao DNA. Envelhecimento Celular. Histonas. Imunossenescência. Leucócitos Mononucleares. Macrófagos. Mitocôndrias. Obesidade. Sistema Imunológico. 
PFEIFER, Lucinéia Orsolin. Efeitos de um programa de treinamento de potência muscular no equilíbrio corporal e capacidade funcional de idosos com diabetes mellitus tipo 2. Orientador: Ronei Silveira Pinto. 2017. 97 f. il. Dissertação (Mestrado em Ciências do Movimento Humano) - Escola de Educação Física, Fisioterapia e Dança, Universidade Federal do Rio Grande do Sul, Porto Alegre, 2017. Disponível em: http://hdl.handle.net/10183/170224. Acesso em: 28 abr. 2019.

resumo

O objetivo do presente estudo foi avaliar o efeito de um programa de treinamento de potência muscular na capacidade funcional e equilíbrio, na função neuromuscular, no perfil lipídico, controle glicêmico e no nível de qualidade de vida de idosos com diabetes mellitus tipo 2 (DM2). Para tanto, foram avaliados 21 sujeitos (68,2 $\pm 3,1$ anos), divididos em dois grupos: grupo intervenção (GI) $(n=11)$ e grupo controle $(\mathrm{GC})(\mathrm{n}=10)$. Os sujeitos do GI realizaram treinamento de potência muscular, com sessões bissemanais, o GC realizou alongamento muscular, uma vez na semana, ambos por um período de 12 semanas. $O$ treino de potência muscular foi realizado para os principais grupos musculares, sendo os exercícios executados da maneira mais rápida possível durante a fase concêntrica. O grupo muscular alvo foi o quadríceps. As variáveis dependentes foram avaliadas antes (momento 1), 8 semanas (momento 2 - equilíbrio dinâmico e estático) e após (momento 3) o período de intervenção O GC realizou alongamento muscular de membros superiores, tronco e membros inferiores. Para a análise dos dados foi utilizado um teste t de Student para comparação dos grupos no momento pré treinamento, para amostras independentes. A comparação de médias foi realizada com ANOVA de duas vias para medidas repetidas, utilizando um post hoc de Bonferroni para as variáveis que foram realizadas em três momentos. Os efeitos avaliados foram os fatores tempo e grupo, bem como a interação desses fatores. Para as variáveis colesterol LDL e potência de pico (calculada por fórmula), como houve diferença entre os grupos pré-treinamento, foi realizada uma ANCOVA. Um nível de significância de $\alpha \leq 0,05$ foi adotado para as análises. Os resultados demonstraram que houve uma melhora significativa $(\mathrm{p} \leq 0,05)$ para o GI na variável de equilíbrio dinâmico, avaliada pelo teste de alcance funcional, do momento 2 para o momento 3 , após as 12 semanas de treinamento, o GC não apresentou modificações $(p>0,05)$ em nenhum dos três momentos. As variáveis de equilíbrio estático não apresentaram efeitos significativos $(p>0,05)$. Na bateria de testes Short Physical Performance Battery (SPPB), o GI apresentou uma diminuição no tempo para a realização do teste de velocidade da marcha $(p<0,05)$ após as 12 semanas de intervenção. No teste de levantarse da cadeira, 
houve um efeito significativo do tempo $(\mathrm{p}<0,05)$, bem como, no score total da bateria de testes SPPB ( $p=0,001)$, em que os dois grupos demonstraram melhoras pós-treinamento. A espessura muscular e qualidade muscular apresentaram um efeito do tempo $(\mathrm{p}<0,05)$, demonstrando que ambos os grupos apresentaram melhoras. A variável neuromuscular de eco intensidade não apresentou efeito significativo ( $p>0,05)$, bem como a variável de composição corporal, gordura visceral. Para o teste de força dinâmica, realizado através do teste de 1 repetição máxima (1-RM) houve um incremento significativo, após 12 semanas de treinamento para o GI $(\mathrm{p}<0,05)$. O pico de torque apresentou efeito do tempo significativo $(\mathrm{p}<0,05)$ em ambos os grupos. Quanto à taxa de produção de torque não foram identificados efeitos significativos $(p>0,05)$. No salto com contra movimento (CMJ) ocorreu um ganho significativo $(p<0,05)$, em que o GI apresentou incrementos pós 12 semanas de treinamento, as outras variáveis do salto (potência média e potência de pico) apresentaram efeitos significativos $(\mathrm{p}<0,05)$, quando calculadas por fórmula. A hemoglobina glicada e o LDL melhoraram significativamente $(\mathrm{p}<0,05)$ para os dois grupos, após o treinamento. Para as demais variáveis sanguíneas não foi encontrado valores significativos. A qualidade de vida, avaliada pelo questionário de avaliação da qualidade de vida no diabetes (DQOL) demonstrou melhora significativa $(p<0,05)$ para o GC após intervenção, não ocorrendo o mesmo com o GI. Por fim, o treinamento de potência muscular foi eficaz para demonstrar ganhos significativos nos testes de equilíbrio dinâmico, na bateria de testes funcionais e no $\mathrm{CMJ}$.

palavras-chave

Diabetes Mellitus Tipo 2. Idoso. Musculação. Treinamento de Força.

ROSSETTO, Caroline. Internações e óbitos de idosos por condições sensíveis à atenção primária no Brasil: uma análise temporal. Orientador: Idiane Rosset. 2018. 78 f. Dissertação (Mestrado em Enfermagem) - Escola de Enfermagem, Universidade Federal do Rio Grande do Sul, Porto Alegre, 2018. Disponível em: http:// hdl.handle.net/10183/178222. Acesso em: 28 abr. 2019.

resumo

Introdução: o aumento da população idosa é uma realidade em todo o mundo. Investigar Internações e óbitos por Condições Sensíveis à Atenção Primária (CSAP) em idosos traz informações essenciais à prática da Atenção Primária à Saúde (APS). Objetivo: analisar a evolução temporal das principais 
causas de internações e óbitos por CSAP de idosos brasileiros no período de 2006 a 2016. Método: estudo ecológico de série temporal, com utilização de dados do Departamento de Informática do Sistema Único de Saúde (DATASUS) e do Instituto Brasileiro de Geografia e Estatística (IBGE). Analisaram-se dados das Autorizações de Internação Hospitalar (AIH) dos hospitais do SUS e ou conveniados, referentes às principais causas de CSAP de idosos brasileiros no período de 2006 a 2016 em todo o país. Os idosos foram subdivididos em dois grupos etários, de 60-79 anos, e $\geq 80$ anos. Foram elencadas as nove causas mais frequente e presentes no início e no fim do período do estudo. O programa Tab para Windows (TABWIN) foi utilizado para as tabulações das variáveis. O programa R Project, versão 3.4.0., e o programa SPSS for Windows, versão 20.0, foram utilizados para as análises estatísticas. O teste de Spearman foi aplicado, para conferir o sentido da tendência, crescente ou decrescente, a força de correlação, e o valor de $\mathrm{p}<0,05$ foi adotado como estatisticamente significativo. Este estudo dispensou apreciação de Comitê de Ética em Pesquisa (CEP), por tratar-se de dados de domínio público. Resultados: no período do estudo houve redução no total das internações por CSAP selecionadas, em idosos brasileiros A Insuficiência Cardíaca (IC) foi a causa mais frequente de internação e óbito, contudo apresentou tendência decrescente no período. As internações por Doenças Pulmonares (DPS), as Gastroenterites Infecciosas (GEA) e a Hipertensão Arterial Sistêmica (HAS) também apresentaram tendência decrescente. Ao analisar as ICSAP por sexo, verificou-se uma frequência maior entre as idosas para a Diabetes Mellitus (DM), GEA e HAS. Em ambos os grupos etários as internações por Infecções do Trato Urinário (ITU), Doenças Cerebrovasculares (DCV), Angina (AGN), Pneumonias (PNM), DM apresentaram uma tendência crescente, enquanto que as demais (IC, DPS, GEA e HAS) apresentaram tendência decrescente. Óbitos por DM, AGN, ITU e PNM apresentaram aumento durante o tempo. Os óbitos por GEA e Deficiências Nutricionais (DNT) foram as duas causas de óbitos que apresentaram tendência decrescente. Observou- se os óbitos por sexo e a PNM, ITU, DCV, DM, Úlcera Gastrointestinal (UGI), apresentaram tendência crescente, em ambos os grupos, as GEA apresentaram tendência decrescente. As IC, DPS e DNT apresentaram tendência crescente, para os idosos mais velhos, e tendência decrescente em idosos jovens. $\mathrm{O}$ total dos dias de permanência obteve aumento no durante o tempo. Considerações Finais: este estudo indica uma redução no total das ICSAP em idosos. Esses achados podem estar relacionados à ampliação e cuidados mais efetivos prestados pela APS, bem como consolidação do SUS. 
SEKINE, Leo. Protocolos de terapia de indução em pacientes portadores de mieloma múltiplo em primeira linha de tratamento: revisão sistemática e metanálise por mixed treatment comparison. Orientador: Rodrigo Antonini Ribeiro. Co-Orientador: Patricia Klarmann Ziegelmann. 2018. 130 f. Tese (Doutorado em Epidemiologia) - Faculdade de Medicina, Universidade Federal do Rio Grande do Sul, Porto Alegre, 2018. Disponível em: http://hdl.handle.net/10183/179021. Acesso em: 28 abr. 2019.

resumo

Introdução: o mieloma múltiplo (MM) é uma enfermidade de crescente incidência devido à melhora da expectativa de vida de diversas populações ao redor do mundo. Seu tratamento é composto por duas estratégias primordiais que separam os pacientes recém-diagnosticados em dois grupos: aqueles elegíveis a transplante de células progenitoras hematopoéticas autólogo (TCPH-Auto) e aqueles que não o são. Tal divisão é determinada por fatores inerentes ao paciente, como idade, performance status e comorbidades. O número de tratamentos disponíveis para esta doença tem se multiplicado de forma rápida nos últimos anos. Devido a diversos fatores logísticos e econômicos, a comparação simultânea dessas abordagens terapêuticas em um ensaio clínico randomizado (ECR) é improvável. Dessa forma, a comparação de eficácia e segurança entre estes diversos protocolos, no intuito de determinar a melhor opção, só pode ser alcançada através de ferramentas como a revisão sistemática (RS) seguida por metanálise em rede. Métodos: com base nessa premissa, realizamos uma RS e metanálise em rede por mixed treatment comparison (MTC) compreendendo tratamentos citotóxicos de indução (primeira linha) para pacientes com diagnóstico recente de MM. Este estudo utilizou-se da já estabelecida divisão terapêutica deste seguimento de pacientes: elegíveis e inelegíveis a TCPH-Auto. A revisão sistemática utilizou uma estratégia de busca sensível com incorporação de um filtro para ECR e consultou as bases de dados PubMed/MEDLINE, EMBASE, Cochrane CENTRAL SciELO e LILACS. Ao todo, foram avaliadas 15.091 referências após a retirada de duplicatas. Tais referências foram então revisadas por pares de pesquisadores de forma paralela, para inclusão em um dos dois grupos em avaliação. Resultados: o estudo de pacientes elegíveis selecionou 18 publicações envolvendo 9 ECR, totalizando 4.432 pacientes arrolados entre 10 abordagens diferentes de tratamento. 
Similaridade entre tratamentos pareceu adequada em relação ao delineamento, metodologia e amostra selecionada. Homogeneidade e consistência não puderam ser aferidas devido à rede apresentar apenas comparações indiretas. $\mathrm{O}$ desfecho de sobrevida global (SG) apontou o PAD (bortezomibe, 14 doxorrubicina e dexametasona) como protocolo de melhor resultado em relação aos demais tratamentos, enquanto o VTD (bortezomibe, talidomida e dexametasona) foi o melhor protocolo no que tange a sobrevida livre de progressão (SLP). Na análise de perfil de resposta ao tratamento, a resposta completa e a resposta global (desfecho combinado de níveis diferenciados de resposta, incluindo a completa) também se mostrou mais frequente com o esquema VTD. Uma análise de segurança foi realizada compreendendo eventos adversos de grau 3 e 4 infeciosos, cardíacos, gastrointestinais, neurológicos, trombóticos e hematológicos. O risco de eventos trombóticos foi maior com o esquema TAD (talidomida, doxorrubicina e dexametasona), neurológicos com o PAD, infecciosos com o Dex (altas doses de dexametasona), hematológicos com o Z-Dex (idarrubicina e dexametasona), gastrointestinais com o VTD e cardíacos com o PAD. Um desfecho combinado considerando os ranqueamentos (probabilidades de ser o melhor tratamento) dos tratamentos para cada um dos desfechos (realizado através do SUCRA - surface under the cumulative ranking curve) foi calculado para os desfechos de sobrevida, resposta e toxicidade e indicou o VTD, seguido pelo PAD e TAD como os melhores tratamentos em geral. Resultados: o estudo de pacientes elegíveis selecionou 18 publicações envolvendo $9 \mathrm{ECR}$, totalizando 4.432 pacientes arrolados entre 10 abordagens diferentes de tratamento. Similaridade entre tratamentos pareceu adequada em relação ao delineamento, metodologia e amostra selecionada. Homogeneidade e consistência não puderam ser aferidas devido à rede apresentar apenas comparações indiretas. O desfecho de sobrevida global (SG) apontou o PAD (bortezomibe, 14 doxorrubicina e dexametasona) como protocolo de melhor resultado em relação aos demais tratamentos, enquanto o VTD (bortezomibe, talidomida e dexametasona) foi o melhor protocolo no que tange a sobrevida livre de progressão (SLP). Na análise de perfil de resposta ao tratamento, a resposta completa e a resposta global (desfecho combinado de níveis diferenciados de resposta, incluindo a completa) também se mostrou mais frequente com o esquema VTD. Uma análise de segurança foi realizada compreendendo eventos adversos de grau 3 e 4 infeciosos, cardíacos, gastrointestinais, neurológicos, trombóticos e hematológicos. O risco de eventos trombóticos foi maior com o esquema TAD (talidomida, doxorrubicina e dexametasona), neurológicos com o PAD, infecciosos com o Dex (altas doses de dexametasona), hematológicos com o Z-Dex (idarrubicina e dexametasona), gastrointestinais com o VTD e 
cardíacos com o PAD. Um desfecho combinado considerando os ranqueamentos (probabilidades de ser o melhor tratamento) dos tratamentos para cada um dos desfechos (realizado através do SUCRA - surface under the cumulative ranking curve) foi calculado para os desfechos de sobrevida, resposta e toxicidade e indicou o VTD, seguido pelo PAD e TAD como os melhores tratamentos em geral. Nosso estudo mostrou que para os tratamentos de primeira linha em pacientes elegíveis a TCPH-Auto a melhor opção de tratamento envolveria o uso de um triplet (tratamento composto por três drogas), principalmente incluindo o uso de novos agentes: drogas imunomodulatórias (IMiDs) e inibidores do proteasoma (PIs). O estudo de pacientes inelegíveis selecionou 54 publicações envolvendo $27 \mathrm{ECR}$, totalizando 11.967 pacientes arrolados entre 23 abordagens diferentes de tratamento. Similaridade entre tratamentos pareceu adequada em relação ao delineamento, metodologia e amostra selecionada. Foi encontrada heterogeneidade moderada a alta entre os estudos que comparavam os mesmos tratamentos para os desfechos de sobrevida (SG e SLP) e para 3 desfechos de toxicidade (hematológico, gastrointestinal e cardíaco). Não foi encontrada inconsistência entre as evidências diretas e indiretas das medidas de efeito que compuseram a medida da MTC. Análise de SG identificou a superioridade do VRd (bortezomibe, lenalidomida e dexametasona), VMPT-VT (bortezomibe, melfalano, prednisona e talidomida), MPR-R (melfalano, prednisona, lenalidomida), Ldc (lenalidomida e dexametasona) e CPR (ciclofosfamida, prednisona e lenalidomida). A SLP foi maior com MPR-R, seguido do MPT-T (melfalano, 15 prednisona e talidomida), VMPT-VT, Ldc e VRd. A resposta completa foi mais comum com regimes contendo bortezomibe (VMPT-VT, VTP - bortezomibe, talidomida e prednisona, VMP - bortezomibe, melfalano e prednisona, $\mathrm{Vd}$ - bortezomibe e dexametasona, e VRd), enquanto a resposta global foi liderada também pelo VMPT-VT, seguido por Vd, VTd (bortezomibe, talidomida e dexametasona), LD (lenalidomida e dexametasona em altas doses) e VTP. Um desfecho compilado de toxicidade (hematológica, gastrointestinal, neurológica, cardíaca, trombótica e infecciosa) apontou o Dex e o MP (melfalano e prednisona) como os regimes mais com a menor incidência de eventos adversos, embora também tenham sido os tratamentos com os piores resultados no quesito sobrevida e resposta. Uma vez ponderadas as diversas probabilidades de ser o melhor tratamento, considerando sobrevida, resposta e toxicidade, ficou indicado o regime VMPT-VT como a melhor abordagem terapêutica, seguida do VRd, MPR-R, VMP e Ldc. Por outro lado, os regimes com piores posicionamentos foram o Dex, TD (talidomida e dexametasona em altas doses), VMPC (vincristina, melfalano, prednisona e ciclofosfamida) com ou sem prednisona contínua, MP e MD (melfalano e dexametasona). Conclusão: os 
resultados do presente trabalho favorecem o uso de esquemas triplets e triplets ou quadruplets (contendo agentes IMiDs e PIs) para pacientes elegíveis e inelegíveis a TCPH-Auto, respectivamente. Além disso, para os pacientes inelegíveis, estratégias que incluam o uso continuado de lenalidomida, devem ser priorizadas em relação a outros esquemas.

\section{palavras - chave}

Autoantígenos. Idoso Fragilizado. Mieloma Múltiplo. Quimioterapia de Indução. Revisão. Transplante.

SILVA, Larissa Xavier Neves da. Adaptações neuromusculares ao treinamento concorrente com e sem a execução de séries máximas em homens idosos. Orientador: Eduardo Lusa Cadore. 2017. 78 f. il. Dissertação (Mestrado em Ciências do Movimento Humano) - Escola de Educação Física, Fisioterapia e Dança, Universidade Federal do Rio Grande do Sul, Porto Alegre, 2017. Disponível em: http://hdl.handle.net/10183/165483. Acesso em: 28 abr. 2019.

resumo

Introdução: o envelhecimento está associado a perdas cardiorrespiratórias e neuromusculares, que estão relacionadas com quedas, hospitalizações e perda da independência funcional. $\mathrm{O}$ treinamento concorrente (TC) já está estabelecido como a melhor ferramenta para combater estes declínios e, portanto, deve-se entender a melhor forma de prescrever este treinamento. Com relação a parte neuromuscular do TC, o uso de repetições máximas (RM) vem sendo questionado sobre sua eficácia e, em idosos, ainda não existem estudos abordando este tema. Objetivo: investigar possíveis diferenças nas adaptações neuromusculares à execução ou não execução de repetições máximas nos exercícios de força, explorando também o uso do volume equalizado (número de repetições igualadas com as repetições máximas), durante o TC em homens idosos. Materiais e métodos: o estudo contou com 12 semanas de TC feito duas vezes na semana; 32 homens idosos foram randomizados para um dos três diferentes grupos: grupo com repetições máximas (GRM); grupo com repetições submáximas (GRNM), que trabalhava com $50 \%$ do volume do GRM; e um grupo que trabalhava com volume equalizado (GRNMVE), ou seja, mesmo volume do GRM, porém com ausência de séries chegando até a falha concêntrica. As variáveis analisadas foram o $1 \mathrm{RM}(\mathrm{kg})$ no exercício LG e EJ, CIVM dos extensores de joelho direito no dinamômetro isocinético, na qual foram avaliados: PTIso, TPT nos intervalos 0-50, 0100 e 0-250 m.s e EMG $(\mu \mathrm{V})$ 
do músculo RF e VL, desempenho de saltos CMJ e SJ, avaliados no tapete de saltos e EM do quadríceps por US. A análise estatística dos dados está apresentada em média e DP. Todas as análises foram feitas no software SPSS 21.0, com nível de significância de $\alpha<0,05$ para todas as variáveis. O TE, que foi calculado pela diferença na média pré e pós treinamento da variável dividido pelo DP pré treinamento. Resultados: todos os grupos incrementaram seus valores de base para o período pós treinamento. Para a força máxima, 1RM LG e EJ incrementaram em todos grupos ( $p<0,05$ e $p<0,001$, respectivamente), sem diferenças entre eles (ganhos $\sim 50 \%$ e $~ 30 \%$ para LG e EJ, respectivamente). O PTI so teve incrementos, mas não significativos, $(p=0,072$; incrementos de $5-15 \%)$. Para a TPT 0-50m.s ( $\mathrm{p}=0,066)$ não teve ganhos significativos, porém os intervalos da TPT 0-100 ( $\mathrm{p}=0,027$; ganhos $15 \%$ ) e TPT 0-250m.s ( $<<0,05$; ganhos $\sim 12 \%$ ) foram significativos para todos os grupos. Para o desempenho de saltos, o CMJ teve uma tendência significativa ( $p=0,056$; ganhos de 3-12\%) e o SJ teve incrementos significativos ( $p<0,05$; ganhos $15 \%$ ), para todos os grupos, sem diferenças entre os grupos. Para os valores de EMG RF e EMG VL ( $p>0,05$ para ambos), não houve incremento em todos os grupos. Para os valores de EM, todos os grupos aumentaram seus valores, sem diferenças entre os grupos, de modo significativo $(\mathrm{p}<0,05)$, com exceção ao VI, que não teve ganhos significativos (VI: $p=0,85$ ), sem diferenças entre os grupos. Para o somatório do quadríceps, todos os grupos incrementaram seus valores significativamente ( $\mathrm{p}<0,05$; ganhos de $2-10 \%)$, sem diferenças entre os grupos. Para a tensão específica, todos os grupos incrementaram seus valores significativamente ( $\mathrm{p}<0,001$; ganhos de $11-29 \%)$, sem diferenças entre eles. Conclusões: o uso de repetições máximas no treino de força (TF), dentro do contexto do TC, em idosos, não é necessário, já que não foi observada vantagem no GRM. Mesmo um menor volume de treinamento foi capaz de induzir a mesma magnitude de adaptações.

palavras-chave

Homens. Idoso. Treinamento de Força.

SILVA, Roberto Pacheco da. Gravidade da apneia obstrutiva do sono e treinamento resistido - efeito em idosos: um ensaio clínico randomizado piloto. Orientador: Denis Martinez. 2018. 165 f. il. Tese (Doutorado em Cardiologia e Ciências Cardiovasculares) - Faculdade de Medicina, Universidade Federal do Rio Grande do Sul, Porto Alegre, 2018. Disponível em: http://hdl.handle.net/10183/179773. Acesso em: 28 abr. 2019. 
Introdução: a prevalência da apneia obstrutiva do sono (AOS) entre pessoas com mais de 70 anos atinge até $95 \%$. As opções de tratamento incluem o uso de pressão positiva nas via aérea, dispositivos intraorais e mudança de estilo de vida. Programa de exercícios aeróbicos ou combinados mostrou reduzir o índice de apneia-hipopneia (IAH) em adultos de meia-idade. No entanto, o efeito do treinamento resistido sobre a gravidade da AOS de pessoas idosas é controverso. O objetivo do presente estudo é avaliar o impacto do treinamento resistido no IAH e identificar possíveis mediadores do efeito do exercício. Métodos: Estudo randomizado, mascarado, controlado, em grupo paralelo. Indivíduos entre 65 e 80 anos, com IAH entre 20 e 50 eventos/hora na poligrafia respiratória foram atribuídos aleatoriamente para 12 semanas de treinamento de força ou grupo controle. IAH foi o principal desfecho. Índice de massa corporal (IMC) e teor de água corporal foram testados como mediadores. Espessura do músculo, força máxima e função física também foram avaliadas. Resultados: A amostra incluiu 23 indivíduos, 57\% homens, com média de idade de $71 \pm 5$ anos, alocados para treinamento $(n=12)$ e grupo controle $(n=11)$. O IAH basal nos grupos de treinamento e controle foi, respectivamente, $30 \pm 7 / \mathrm{h}$ e $29 \pm 9 / \mathrm{h}$. No seguimento, o IAH mostrou significativa interação tempo $\times$ grupo. Não foi observada correlação entre Delta IAH e Delta IMC ou Delta teor de água corporal. A interação tempo × grupo permanece significativa após ajustar o modelo GEE para esses possíveis mediadores. Conclusão: treinamento resistido a curto prazo em pessoas idosas é viável e muda de forma favorável a severidade da AOS e desfechos funcionais. As alterações no IMC e no teor de água corporal não parecem mediar a redução da IAH. Estudos futuros em amostras maiores de pessoas idosas são necessários.

palavras - chave

Apneia Obstrutiva do Sono. Ensaio Clínico. Exercício. Força Muscular. Idoso. Terapia por Exercício.

SILVEIRA, Erik Menger. Adaptações cardiovasculares e funcionais ao treinamento concorrente com e sem a execução de séries com repetições máximas em homens idosos. Orientador: Eduardo Lusa Cadore. 2017. 71 f. il. Dissertação (Mestrado em Ciências do Movimento Humano) - Escola de Educação Física, Fisioterapia e Dança, Universidade Federal do Rio Grande do Sul, Porto Alegre, 2017. Disponível em: http://hdl.handle.net/10183/164796. Acesso em: 28 abr. 2019. 
O objetivo da presente dissertação foi avaliar e comparar as possíveis diferenças nas adaptações cardiovasculares e funcionais ao treinamento concorrente com e sem a execução de séries com repetições até a falha concêntrica em homens idosos. Trinta e dois homens idosos saudáveis $(67,4 \pm 4,1)$ foram alocados randomicamente em três grupos diferentes de treinamento concorrente: Treinamento de força utilizando repetições máximas $(G R M, n=12)$, Treinamento de força com repetições submáximas (GRNM, $n=11)$ e Treinamento de força com repetições submáximas com volume equalizado ao realizado pelo GRM (GRNMV, $n=9$ ). Os participantes treinavam duas vezes por semana, durante doze semanas, executando o treinamento aeróbico imediatamente após o treinamento de força. Antes e após a intervenção foi avaliado o Vo2pico através de ergoespirometria, o desempenho funcional utilizando os testes timed up and go (TUG), sentar e levantar 5 vezes (SeL) e preensão manual (PM). Coletou-se amostras de sangue para análise da glicemia, colesterol total, HDL, LDL e triglicerídeos. A pressão arterial sistólica (PAS) e pressão arterial diastólica (PAD) foram mensuradas através de método auscultatório, o desempenho de saltos através do salto agachado (SJ) e salto com contra movimento (CMJ) e a composição corporal avaliada a partir de antropometria. Após a intervenção, foi observado um efeito tempo significativo $(p<0,05)$ no Vo2pico, sem diferenças entre os grupos. No desempenho funcional não foram observadas mudanças em nenhum dos testes. A análise sanguínea demonstrou um efeito tempo significativo $(\mathrm{p}<0,01)$ no HDL, sem diferenças entre os grupos, enquanto não houve variações para glicemia, LDL e triglicerídeos. Na altura dos saltos, foi verificado um efeito tempo significativo $(\mathrm{p}<0,01)$ no SJ e uma tendência a incremento $(p<0,056)$ no $C M J$, sem diferenças entre os protocolos de treinamento. A composição corporal foi alterada pelo treinamento, com efeito significativo na massa de gordura relativa $(\mathrm{p}<0,001)$, na massa livre de gordura relativa $(p<0,001)$ e no somatório de dobras cutâneas $(p<0,001)$, sem diferenças entre os grupos. Desta forma, foi observado que todos os protocolos de treinamento foram eficazes para promover mudanças na capacidade aeróbica, no perfil lipídico, no desempenho de saltos e na composição corporal, porém, o GRNM foi mais eficiente, pois promoveu tais adaptações com um volume de treino menor.

palavras-chave

Antropometria. Idoso. Treinamento Aeróbico. Treinamento de Força. 
STROGULSKI, Nathan Ryzewski. Decanoato de nandrolona e AMPK modulam a macroautofagia e bioenergética cerebral no envelhecimento. Orientador: Luis Valmor Cruz Portela. 2018. 70 f. il. Dissertação (Mestrado em Bioquímica) - Instituto de Ciências Básicas da Saúde, Universidade Federal do Rio Grande do Sul, Porto Alegre, 2018. (Texto não disponível on-line).

resumo

Sabe-se que alterações na homeostase energética e proteica ao longo do envelhecimento, estão associadas com doenças neurodegenerativas. Fisiologicamente, a mitocôndria funciona como uma organela integradora do metabolismo energético oxidativo influenciando o sistema de depuração de proteínas desenoveladas e organelas disfuncionais, autofagia. O envelhecimento pode levar à ruptura funcional destes sistemas resultando em prejuízos neuroenergéticos e acúmulo de proteínas tóxicas. Neste sentido, o declínio nos níveis de testosterona, um hormônio anabólico, tem sido proposto como um potencializador do declínio das funções fisiológicas no envelhecimento. O objetivo deste estudo foi investigar se a suplementação com decanoato de nandrolona (ND), um derivado sintético da testosterona, em animais envelhecidos melhora o metabolismo energético mitocondrial e mecanismos autofágicos. Camundongos machos albino CF1 de 3 e 18 meses foram submetidos à análise basal de captação de fluorodesoxiglicose (18FDG) através de tomografia por emissão de pósitrons (microPET-FDG). Posteriormente eles foram alocados em 4 grupos que receberam uma injeção diária subcutânea de ND (15mg/kg; Grupos 3m/ND e 18m/ND) ou veículo oleoso (VEH) (Grupos 3m/VEH; 18m/VEH), durante 15 dias. Os animais foram resubmetidos à análise de microPET-FDG, e logo após a eutanásia foi realizada a respirometria de alta resolução, para avaliação funcional dos estados de respiração mitocondrial em preparações de sinaptossomas. Para tanto, utilizamos um protocolo com substratos energéticos, um desacoplador e inibidores do sistema de transporte de elétrons. Ainda, os imunoconteúdos hipotalâmicos de AMPK e pAMPKT172, bem como de LC3 foram avaliados como biomarcadores de homeostase energética e de fluxo autofágico, respectivamente. Os resultados demonstram que os camundongos envelhecidos não apresentaram alterações significativas na captação cerebral de 18FDG e nos estados de respiração mitocondrial. Também, os animais envelhecidos apresentaram menor razão pAMPKT172/AMPK, Beclin-1, BCL-2 e LC3II/LC3I em relação aos animais jovens controle. A suplementação de ND nos animais jovens aumentou a captação de 18FDG e o consumo de oxigênio no estado routine sem influenciar os outros estados mitocondriais. A ND nos animais envelhecidos não aumentou a captação de 18FDG, e nem o consumo de oxigênio nos estados mitocondriais. Nos animais envelhecidos a ND aumentou 
a razão pAMPKT172/AMPK e LC3II/LC3I, bem como a eficiência da fosforilação oxidativa mitocondrial. Observamos que este mecanismo não se dá por modulação de Beclin-1. Nossos resultados sugerem que envelhecimento não culmina necessariamente em modificações funcionais da capacidade energética cerebral, embora os biomarcadores moleculares de estado energético e fluxo autofágico estejam diminuídos. A ND melhorou a eficiência bioenergética mitocondrial e o fluxo autofágico sem aumentar a captação de 18FDG. Estes benefícios são provavelmente mediados pela reprogramação da sinalização via AMPK.

palavras-chave

Autofagia. Nandrolona. Proteínas Quinases Ativadas por AMP. Mitocôndrias. Envelhecimento. Hipotálamo.

TEODORO, Juliana Lopes. Efeitos do treinamento concorrente com e sem a execução de repetições até a falha concêntrica nas adaptações neuromusculares e funcionais em homens idosos. Orientador: Eduardo Lusa Cadore. 2018. 69 f. il. Dissertação (Mestrado em Ciências do Movimento Humano) - Escola de Educação Física, Fisioterapia e Dança, Universidade Federal do Rio Grande do Sul, Porto Alegre, 2018. Disponível em: http://hdl.handle.net/10183/185247. Acesso em: 28 abr. 2019.

resumo

O treinamento concorrente é conhecido como uma alternativa eficiente para promover diversos benefícios fisiológicos além de minimizar os prejuízos causados pelo envelhecimento. Diferentes métodos têm sido investigados com o intuito de otimizar os ganhos gerados pelo treinamento, a partir disso, o treinamento de força com o uso de repetições até a falha concêntrica tem recebido considerável atenção por parte dos pesquisadores. Os resultados encontrados na literatura mostram-se controversos e existem escassos estudos comparando o uso de repetições máximas e submáximas em indivíduos idosos, principalmente em períodos mais longos de intervenção. Assim, o objetivo do presente estudo foi comparar os efeitos do treinamento concorrente com e sem a execução de repetições até a falha concêntrica nas adaptações neuromusculares e funcionais em homens idosos. Métodos: 36 homens idosos sedentários (67,1 $\pm 5,1$ anos) foram randomizados em três grupos: grupo com repetições até a falha (RFG, $n=13$ ), grupo com repetições sem a falha e $50 \%$ do volume de treino de RFG (NFG, $n=12)$, e grupo com repetições sem a falha mas com volume equalizado ao RFG (ENFG, $n=11)$. Os protocolos de treinamento ocorreram 2 vezes por semana, durante 20 semanas. Durante a 
sessão de treino, os indivíduos iniciavam com exercícios de força e em seguida realizavam exercício aeróbico em esteira rolante. Foram realizadas avaliações de uma repetição máxima (1RM) nos exercícios de leg press e extensão de joelhos, pico de torque isométrico (PTiso), taxa de produção de torque (TPT) em 50, 100 e $250 \mathrm{~ms}$ e espessura muscular do vasto lateral, vasto medial, vasto intermédio e reto femoral, também foi avaliada a capacidade funcional através dos testes de sentar e levantar da cadeira e timed up and go (TUG) antes e depois do período de intervenção. Resultados: Após 20 semanas de treinamento, houve incrementos significativos nos valores de 1RM em leg press e extensão de joelhos ( $p<0,001)$, no PTiso ( $<<0,001)$, na TPT (50, 100 e 250ms) $(\mathrm{p} \leq 0,001)$, na espessura muscular do quadríceps $(\mathrm{p}<0,05)$ e no teste de sentar e levantar da cadeira $(p<0,05)$ em todos os grupos, sem diferença significativa entre eles. Conclusão: Os resultados sugerem que o treinamento concorrente com o uso de repetições até a falha concêntrica não promove benefícios adicionais na função muscular e na capacidade funcional de indivíduos idosos. Além disso, realizar exercícios com metade do volume de treinamento com moderada e alta intensidade (65-80\% de 1RM) parece otimizar as adaptações neuromusculares e funcionais após 20 semanas de treinamento.

palavras - chave

Envelhecimento. Músculos. Neurofisiologia. Treinamento Físico.

TRINDADE, Cássia Daniele Zaleski. Parâmetros biomecânicos, fisiológicos e nutricionais de nadadores competitivos da categoria máster. 2018. 101 f. il. Dissertação (Mestrado em Ciências do Movimento Humano) - Escola de Educação Física, Fisioterapia e Dança, Universidade Federal do Rio Grande do Sul, Porto Alegre, 2018. Orientador: Flavio Antonio de Souza Castro. Disponível em: http://hdl. handle.net/10183/184517. Acesso em: 28 abr. 2019.

resumo

Esta dissertação possui o objetivo geral de analisar desempenho, parâmetros antropométricos, biomecânicos, fisiológicos e nutricionais de nadadores máster competitivos em diferentes faixas etárias. Participaram, de uma ou mais fases da pesquisa, 23 atletas máster de natação do sexo masculino, amadores, divididos por percentil de idade $(\mathrm{P})$ em três grupos etários distintos. Os atletas foram avaliados quanto à antropometria e composição corporal; o desempenho, o pico de consumo de oxigênio (VO2pico) e os parâmetros biomecânicos (frequência de braçada, distância por ciclo de braçada, velocidade 
de nado e índice de nado) foram avaliados em um teste de $200 \mathrm{~m}$ nado crawl (T200), sob máxima intensidade. Parâmetros fisiológicos (consumo máximo de oxigênio - VO2max, concentração de lactato sanguínea, frequência cardíaca) e psicofisiológicos (percepção subjetiva ao esforço) foram obtidos de um teste progressivo composto por $n$ repetições de $200 \mathrm{~m}$ nado crawl. Os parâmetros nutricionais foram obtidos a partir de registro alimentar de sete dias. Os dados, entre as faixas etárias, foram comparados por meio de estatística inferencial e calculados os tamanhos de efeito. O desempenho no T200 decai com o a idade, e apresenta correlação com VO2pico e variáveis biomecânicas. VO2max possui grande variabilidade entre os grupos etários, sendo influenciado por outros fatores além da idade. Ademais, nadadores máster de diferentes faixas etárias são muito similares quanto à composição corporal, ingestão e gasto energético.

palavras-chave

Cinemática. Consumo de Oxigênio. Envelhecimento. Natação.

TRINDADE, Jorge Luiz de Andrade. A mobilidade corporal da população rural idosa do Rio Grande do Sul e os riscos de internação hospitalar. Orientador: Alexandre Simões Dias. 2018. 229 f. il. Tese (Doutorado em Ciências do Movimento Humano) - Escola de Educação Física, Fisioterapia e Dança, Universidade Federal do Rio Grande do Sul, Porto Alegre, 2018. Disponível em: http://hdl. handle.net/10183/185798. Acesso em: 28 abr. 2019.

resumo

Em termos de atenção à saúde é reconhecido que a parcela da população que mais utiliza de serviços especializados, como internações hospitalares, são os indivíduos com mais de 60 anos de idade. No Rio Grande do Sul (RS), a maior concentração de idosos se encontra nos municípios pequenos, com menos de 10 mil habitantes e com atividades econômicas relacionadas à produção agrícola. E pouco se sabe sobre essa população, principalmente do idoso aposentado rural, seus riscos de fragilização, sua condição de saúde-doença e utilização de serviços de saúde. Este estudo, então, propôs-se a avaliar a mobilidade corporal da população rural idosa e os riscos de internação hospitalar em diferentes regiões do estado do RS. Para tanto, foi realizada uma pesquisa exploratória de base populacional e delineamento ecológico e transversal. A construção do processo investigatório se deu em 3 etapas. A primeira consistiu em uma pesquisa direta com 604 trabalhadores rurais aposentados e com mais de 60 anos de idade, residentes em diferentes regiões do estado, 
em que, foram avaliadas a mobilidade funcional através do Timed Up and Go Test, a fragilidade referida e a Probabilidade de Internações Repetidas (PIR), através de teste e instrumentos validados para o Brasil. Na segunda parte, foram investigadas as Internações por Condições Sensíveis à Atenção Primária (ICSAP) de pessoas com mais de 60 anos de idade residentes no RS, no ano de 2015, através do departamento de informática do Sistema Único de Saúde do Brasil (DATASUS). Na terceira etapa da pesquisa, foram estabelecidas relações entre ICSAP, PIR, Fragilidade e mobilidade da população idosa rural do estado, considerando a idade, sexo e local ou região de residência. O estudo resultou em 6 artigos: o primeiro, uma revisão da literatura sobre a população rural idosa do RS; o segundo, assim como o terceiro e quarto, foram produtos da primeira etapa do estudo, que resultaram nos títulos Síndrome de fragilidade em idosos rurais no estado do RS, Risco de internação hospitalar em trabalhadores rurais idosos no estado do Rio Grande do Sul e Mobilidade funcional e a fragilidade de idosos agricultores do RS; o quinto artigo é sobre Internações por condições sensíveis à atenção primária de idosos no Rio Grande do Sul e é resultado da segunda etapa da pesquisa; o último artigo, Risco de hospitalização e mobilidade de idosos rurais no Rio Grande do Sul, corresponde à última etapa do estudo, que estabelece relações entre ICSAP no estado, a PIR, a fragilidade referida e a mobilidade da população idosa rural. O processo de investigação, bem como os desfechos, identifica uma população de idosos trabalhadores rurais, jovens em franca atividade, homens em sua maioria, que percebem a sua saúde como frágil e mantêm um baixo risco de internação. O estudo nos mostrou uma relação entre fragilidade, mobilidade funcional e ICSAP compatível com riscos de internação de idosos no estado. Também identificou algumas particularidades em relação a questões de saúde-doença da população rural idosa gaúcha, que sugerem a necessidade de incremento da atenção primária à saúde do trabalhador do campo. No entanto, há necessidade de se promover outras pesquisas com essa população, considerando as suas características culturais, sociais e demandas de políticas sociais adequadas a uma manutenção de qualidade de vida, visto que a área oferece obstáculos em relação a serviços públicos e outros inerentes à condição do envelhecimento no campo. 
ZIBETTI, Murilo Ricardo. Aprendizagem controlada, evocação livre e guiada na avaliação da memória episódica em pacientes com doença de Alzheimer. Orientador: Clarissa Marceli Trentini. 2017. Tese (Doutorado em Psicologia) - Instituto de Psicologia, Universidade Federal do Rio Grande do Sul, Porto Alegre, 2017. Disponível em: http://hdl.handle.net/10183/179784. Acesso em: 28 abr. 2019. (Resumo não disponível on-line).

palavras-chave

Demência. Doença de Alzheimer. Idosos. Memória Episódica. 